US Army Corps of Engineers ${ }_{\circledast}$

Engineer Research and

Development Center

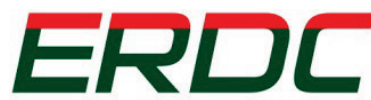

INNOVATIVE SOLUTIONS

for a safer, better world

Ecosystem Management and Restoration Research Program

\title{
Testing and Validation Studies of the NSMII- Benthic Sediment Diagenesis Module
}

Zhonglong Zhang and Billy E. Johnson

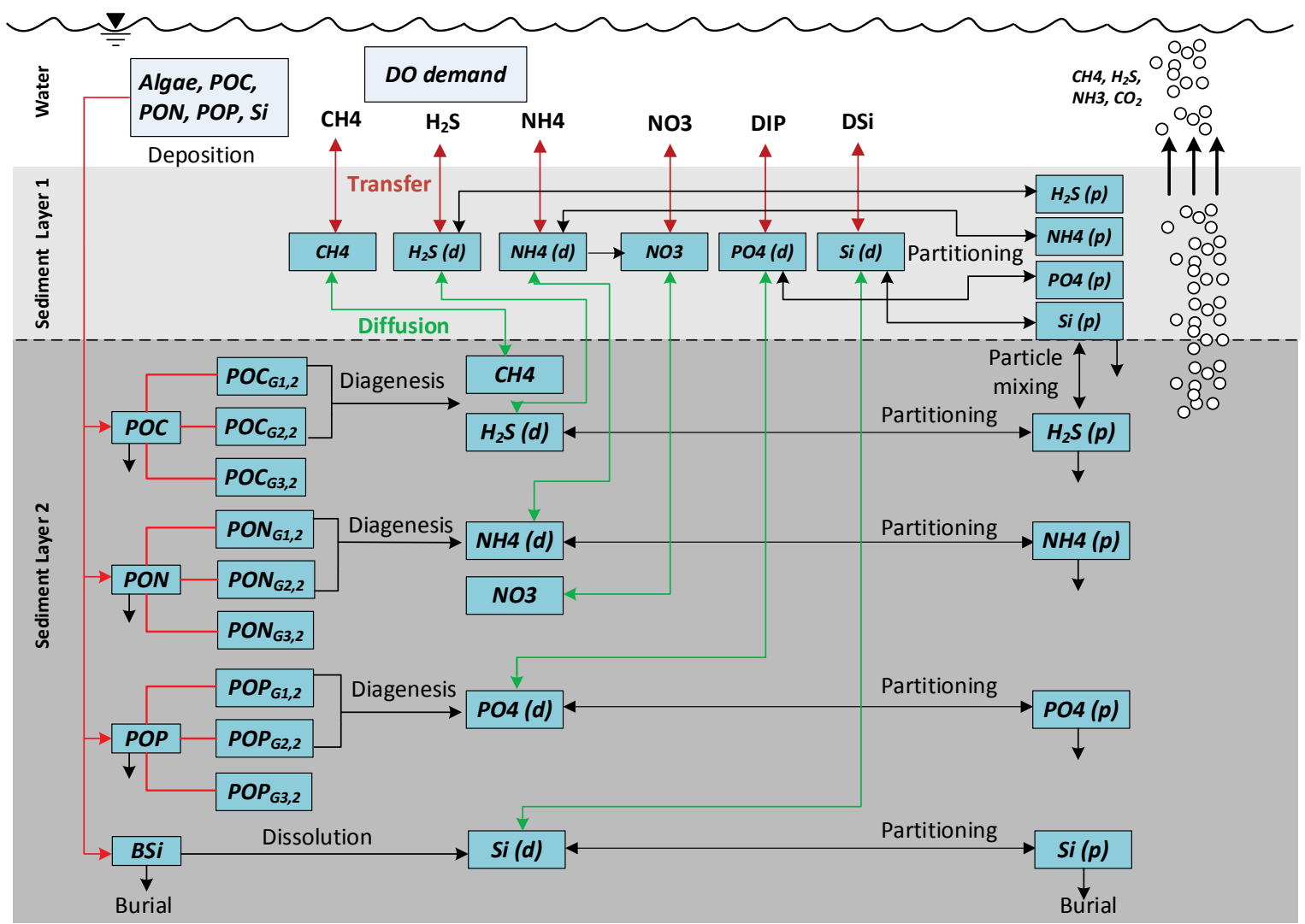

Approved for public release; distribution is unlimited. 
The U.S. Army Engineer Research and Development Center (ERDC) solves the nation's toughest engineering and environmental challenges. ERDC develops innovative solutions in civil and military engineering, geospatial sciences, water resources, and environmental sciences for the Army, the Department of Defense, civilian agencies, and our nation's public good. Find out more at www.erdc.usace.army.mil.

To search for other technical reports published by ERDC, visit the ERDC online library at http://acwc.sdp.sirsi.net/client/default. 


\section{Testing and Validation Studies of the NSMII- Benthic Sediment Diagenesis Module}

Zhonglong Zhang

LimnoTech

501 Davis Drive

Ann Arbor, MI 48108

Billy E. Johnson

Environmental Laboratory

U.S. Army Engineer Research and Development Center 3909 Halls Ferry Road

Vicksburg, MS 39180-6199

Final report

Approved for public release; distribution is unlimited.

Prepared for U.S. Army Corps of Engineers

Washington, DC 20314-1000

Under Project 45745, "Nutrient Simulation Module Development and Integration" 


\section{Abstract}

Nutrient simulation modules (NSMs) have been developed as "plug in" water quality modules for HEC-RAS (Hydrologic Engineering CenterRiver Analysis System) and other hydrologic and hydraulic models. The NSMs model multiple water quality constituents and biogeochemical processes in the water column. The NSMs consist of two modules: NSMI and NSMII, differing mainly in the number of water quality constituents (state variables) and kinetic processes (transformations) included. The benthic sediment diagenesis module was developed as an option module for coupling with the NSMI and NSMII water column kinetics. Sediment-water fluxes of dissolved oxygen and nutrients are computed internally rather than prescribed if the benthic sediment diagenesis module is activated. The ability of the NSMII-benthic sediment diagenesis module to correctly predict sediment-water nutrient fluxes and sediment oxygen demand was validated and evaluated against observed data and existing benthic sediment diagenesis models through a series of case studies. These case studies were chosen for representing various sedimentation and environmental conditions in aquatic systems. The simulated sediment-water nutrient fluxes and sediment oxygen demand over time were generally in good agreement with observed data and two model results for all test cases. This report documents testing and evaluation of the NSMII-benthic sediment diagenesis module. The report describes the testing conditions, model inputs, and model results.

DISCLAIMER: The contents of this report are not to be used for advertising, publication, or promotional purposes. Citation of trade names does not constitute an official endorsement or approval of the use of such commercial products. All product names and trademarks cited are the property of their respective owners. The findings of this report are not to be construed as an official Department of the Army position unless so designated by other authorized documents. 


\section{Contents}

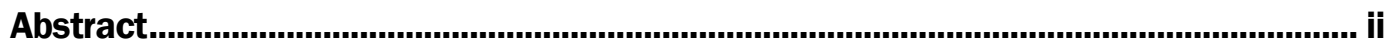

Figures and Tables.......................................................................................................

Preface

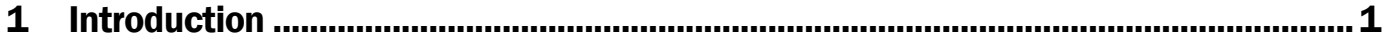

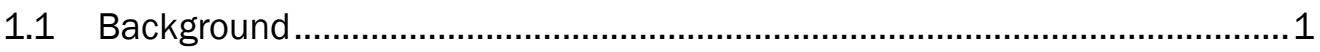

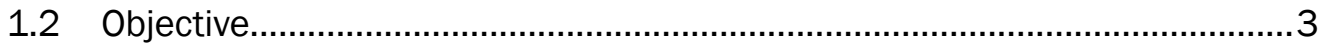

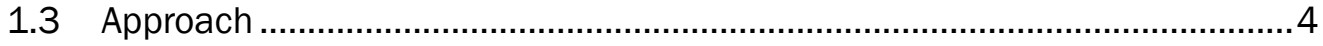

2 Benthic Sediment Diagenesis Module ................................................................ 5

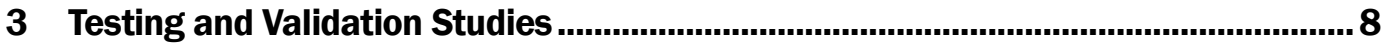

3.1 Model development and result comparisons ............................................... 9

3.1.1 Input data and model development.................................................................. 9

3.1.2 Predictions of sediment organic matter diagenesis fluxes.................................... 14

3.1.3 Predictions of sediment reaction and transfer coefficients .................................. 15

3.1.4 Predictions of sediment concentrations of inorganic constituents........................17

3.1.5 Predictions of sediment oxygen demand and sediment-water fluxes .................. 21

3.2 Special case testing and sensitivity analysis of NSMII................................ 23

3.2.1 NSMII vs. SedFlux steady-state solutions ........................................................ 23

3.2.2 NSMII steady-state vs. unsteady-state solutions................................................. 25

3.2.3 NSMII analytical vs. numerical solutions of sediment methane ...........................2 27

3.2.4 Comparisons of the diagenesis rates of three sediment organic matter

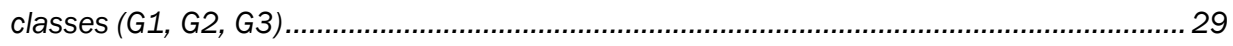

3.2.5 Sensitivities of the water column depositional rates ............................................ 30

3.2.6 Sensitivities of the deep burial velocities .......................................................... 32

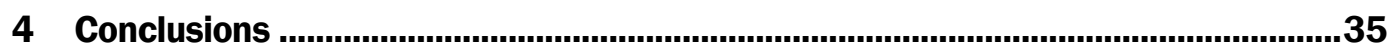

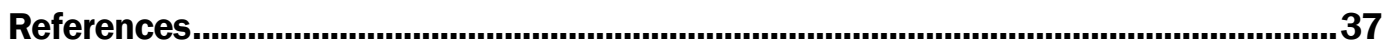

\section{Report Documentation Page}




\section{Figures and Tables}

\section{Figures}

Figure 1. Diagram of water quality state variables and mass transport processes in NSMII.

Figure 2. Schematic overview of the state variables and processes modeled in the benthic sediment diagenesis module.

Figure 3. Time series plots of water column depositional rates: (a) POC, (b) PON, and (c) POP..

Figure 4. Time series plots of the water column concentrations: (a) NH4, (b) NO3, (c) DIP, and (d) DO.

Figure 5. Comparisons of model predictions of the sediment total diagenesis

fluxes: (a) carbon, (b) nitrogen, (c) phosphorous.

Figure 6. Comparisons of model predictions of (a) particle mixing coefficient

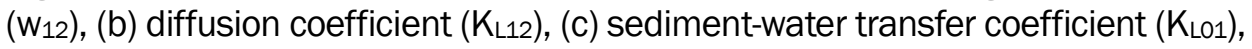
and (d) sediment stress (ST).

Figure 7. Comparisons of model predictions of the sediment layer 2's concentrations: (a) NH4, (b) NO3, (c) TIP, (d) $\mathrm{H}_{2} \mathrm{~S}$, and (e) $\mathrm{CH} 4$.

Figure 8. Comparisons of model predictions of the sediment layer 1's concentrations: (a) NH4, (b) NO3, (c) TIP, (d) $\mathrm{H}_{2} \mathrm{~S}$, and (e) $\mathrm{CH} 4$.

Figure 9. Comparisons of SedFlux and NSMII unsteady-state model predictions of the sediment-water fluxes: (a) SOD, (b) NH4, (c) NO3, (d) DIP, (e) $\mathrm{CH} 4$ and (f) $\mathrm{H}_{2} \mathrm{~S}$.

Figure 10. Comparisons of SedFlux vs. NSMII steady-state solutions: (a) SOD and sediment-water fluxes: (b) NH4, (c) NO3, (d) $\mathrm{CH} 4$, and (e) DIP.

Figure 11. Comparisons of NSMII steady- vs. unsteady-state solutions of sediment layer 2's concentrations: (a) NH4, (b) NO3, (3) DIP, (4) $\mathrm{H}_{2} \mathrm{~S}$, and (c) $\mathrm{CH} 4$.

Figure 12. Comparisons of NSMII analytical vs. numerical solutions of sediment methane: (a) layer 2's CH4, (b) CSOD, (c) CH4 loss, and (d) sediment-water flux of $\mathrm{CH} 4$.

Figure 13. Comparisons of NSMII predictions of the sediment concentrations under the steady- and unsteady-state solutions: (a) POC G1, (b) POC G2, (c) PON G1, (d) PON G2, (e) POP G1, and (f) POP G2. 30

Figure 14. Sensitivities of water column organic matter deposition rates on sediment-water fluxes: (a) SOD, (b) NH4, (c) NO3, (d) $\mathrm{H}_{2} \mathrm{~S}$, and (e) DIP.

Figure 15. Sensitivities of deep burial velocities on the sediment-water fluxes: (a) SOD, (b) NH4, (c) NO3, and (d) DIP.

\section{Tables}

Table 1. Water quality state variables modeled in NSMII.................................................... 1

Table 2. Water quality state variables modeled in the NSMII-benthic sediment diagenesis module. 
Table 3. Initial conditions of benthic sediment diagenesis state variables. ........................ 9

Table 4. Key sediment diagenesis module input parameters and coefficients.................13 


\section{Preface}

This study was conducted as part of the U.S. Army Corps of Engineers (USACE) Ecosystem Management and Restoration Research Program (EMRRP), Project number 45745, "Nutrient Simulation Module Development and Integration." Glenn Rhett was Program Manager of the EMRRP, and Dr. Alfred Cofrancesco was the Technical Director.

This report was prepared by Dr. Zhonglong Zhang of LimnoTech, under contract to the U.S. Army Engineer Research and Development Center (ERDC), and Dr. Billy Johnson of the Water Quality and Contaminant Modeling Branch (WQCMB), Environmental Processes and Engineering Division (EPED), ERDC Environmental Laboratory (EL). Preparation of the report was under the general supervision of Dr. Dorothy Tillman, Chief, WQCMB; Warren P. Lorentz, Chief, EPED; and Dr. Beth Fleming, Director, ERDC-EL.

At the time of publication, COL Bryan S. Green was Commander of ERDC, and Dr. Jeffery P. Holland was Director of ERDC. 


\section{Introduction}

\subsection{Background}

A set of nutrient simulation modules (NSMs) have been developed as "plug in" water quality modules for HEC-RAS (Hydrologic Engineering CenterRiver Analysis System) (HEC 2010) and other hydrologic and hydraulic models (Zhang and Johnson 2016). The NSMs are designed to be independent of the dimensionality of the spatial domain; they model multiple water quality constituents and biogeochemical processes in aquatic systems. The NSMs consist of two kinetics modules: NSMI and NSMII, differing mainly in the number of water quality constituents (state variables) and kinetic processes (transformations) included. They are compiled as NSMI.dll and NSMII.dll, respectively. The NSMII was designed for an advanced water quality simulation. The NSMII models multiple algal groups, benthic algae, nitrogen, phosphorus, and carbon cycles, carbonaceous biochemical oxygen demand, dissolved oxygen, and pathogen. The constituents simulated in NSMII are listed in Table 1. Chla, D, C, N, P and $\mathrm{O}_{2}$ under the units refer to chlorophyll-a, dry weight, carbon, nitrogen, phosphorus, and oxygen, respectively. The colony forming unit (CFU) is a measure of viable bacterial numbers.

Table 1. Water quality state variables modeled in NSMII.

\begin{tabular}{|c|c|c|c|}
\hline Variable & Definition & Units & Option \\
\hline$A_{p i}$ & Algae (Phytoplankton) & $\mu g-C h l a ~ L-1$ & $1-3$ \\
\hline$A_{b}$ & Benthic algae & g-D m-2 & On/Off \\
\hline NO3 & Nitrate & mg-N L-1 & On \\
\hline $\mathrm{NH} 4$ & Ammonium & mg-N L-1 & On \\
\hline$D O N$ & Dissolved organic nitrogen & mg-N L-1 & On \\
\hline$\angle P O N$ & Labile particulate organic nitrogen & mg-N L-1 & On \\
\hline$R P O N$ & $\begin{array}{l}\text { Refractory particulate organic } \\
\text { nitrogen }\end{array}$ & mg-N L-1 & On \\
\hline TIP & Total inorganic phosphorus & $m g-P L^{-1}$ & On \\
\hline$D O P$ & Dissolved organic phosphorus & mg-P L-1 & On \\
\hline$\angle P O P$ & $\begin{array}{l}\text { Labile particulate organic } \\
\text { phosphorus }\end{array}$ & $m g-P L^{-1}$ & On \\
\hline$R P O P$ & $\begin{array}{l}\text { Refractory particulate organic } \\
\text { phosphorus }\end{array}$ & $m g-P L^{-1}$ & On \\
\hline$D / C$ & Dissolved inorganic carbon & $\mathrm{mol} \mathrm{L}-1$ & On \\
\hline
\end{tabular}




\begin{tabular}{|l|l|l|l|}
\hline Variable & \multicolumn{1}{|c|}{ Definition } & \multicolumn{1}{c|}{ Units } & \multicolumn{1}{c|}{ Option } \\
\hline LDOC & Labile dissolved organic carbon & $\mathrm{mg}-\mathrm{C} \mathrm{L}^{-1}$ & On \\
\hline$R D O C$ & Refractory dissolved organic carbon & $\mathrm{mg}-\mathrm{C} \mathrm{L}^{-1}$ & On \\
\hline LPOC & Labile particulate organic carbon & $\mathrm{mg}-\mathrm{C} \mathrm{L}^{-1}$ & On \\
\hline RPOC & $\begin{array}{l}\text { Refractory particulate organic } \\
\text { carbon }\end{array}$ & $\mathrm{mg}-\mathrm{C} \mathrm{L}^{-1}$ & On \\
\hline$C B O D_{i}$ & $\begin{array}{l}\text { Carbonaceous biochemical oxygen } \\
\text { demand }\end{array}$ & $\mathrm{mg}-\mathrm{O}_{2} \mathrm{~L}^{-1}$ & 0-10 \\
\hline$C H 4$ & Methane & $\mathrm{mg}-\mathrm{O}_{2} \mathrm{~L}^{-1}$ & On/Off \\
\hline$H \times S$ & Total dissolved sulfides & $\mathrm{mg}-\mathrm{O}_{2} \mathrm{~L}^{-1}$ & On/Off \\
\hline$D O$ & Dissolved oxygen & $\mathrm{mg}-\mathrm{O}_{2} \mathrm{~L}^{-1}$ & On \\
\hline$B S i$ & Particulate biogenic silica & $\mathrm{mg}-\mathrm{Si} \mathrm{L}^{-1}$ & On/Off \\
\hline$D S i$ & Dissolved silica & $\mathrm{mg}-\mathrm{Si} \mathrm{L}^{-1}$ & On/Off \\
\hline$P X$ & Pathogen & cfu $\left(100 \mathrm{~mL}^{-1}\right.$ & On/Off \\
\hline$A l k$ & Alkalinity & $\mathrm{mg}-\mathrm{CaCO}_{3} \mathrm{~L}^{-1}$ & On/Off \\
\hline
\end{tabular}

Figure 1 provides an overview of the water quality state variables and mass transport processes modeled in the NSMII. Algae may be either floating (phytoplankton) or attached to the bed, in a manner similar to periphyton. Floating algae are subject to sinking while periphyton are subject to substrate limitations. Diatoms are distinguished from other algae in that they need silicate to grow. Organic matter has a fundamental role in water quality processes, which cannot be identified by single lumped organic nitrogen, phosphorus, and carbon state variables alone (Connolly and Coffin 1995, Shanahan et al. 1998, Chapra 1999). Compared to NSMI, NSMII includes dissolved, refractory, and labile particulate organic species. Labile and refractory organic matter distinctions are based upon relative decay rates of the organics. A labile fraction describes organic materials that decay on a time scale of days to weeks, while a refractory fraction accounts for decay processes lasting months to a year. Note that the NSMII splits dissolved organic carbon, particulate organic carbon, nitrogen, and phosphorus into labile and refractory fractions but represents dissolved organic nitrogen and phosphorus as homogenous components. Water quality kinetics for CBOD, pathogen, and alkalinity are modeled in NSMII as for NSMI. Detailed discussion of equations and mechanisms in NSMI and NSMII can be found from Zhang and Johnson (2016). 
Figure 1. Diagram of water quality state variables and mass transport processes in NSMII.

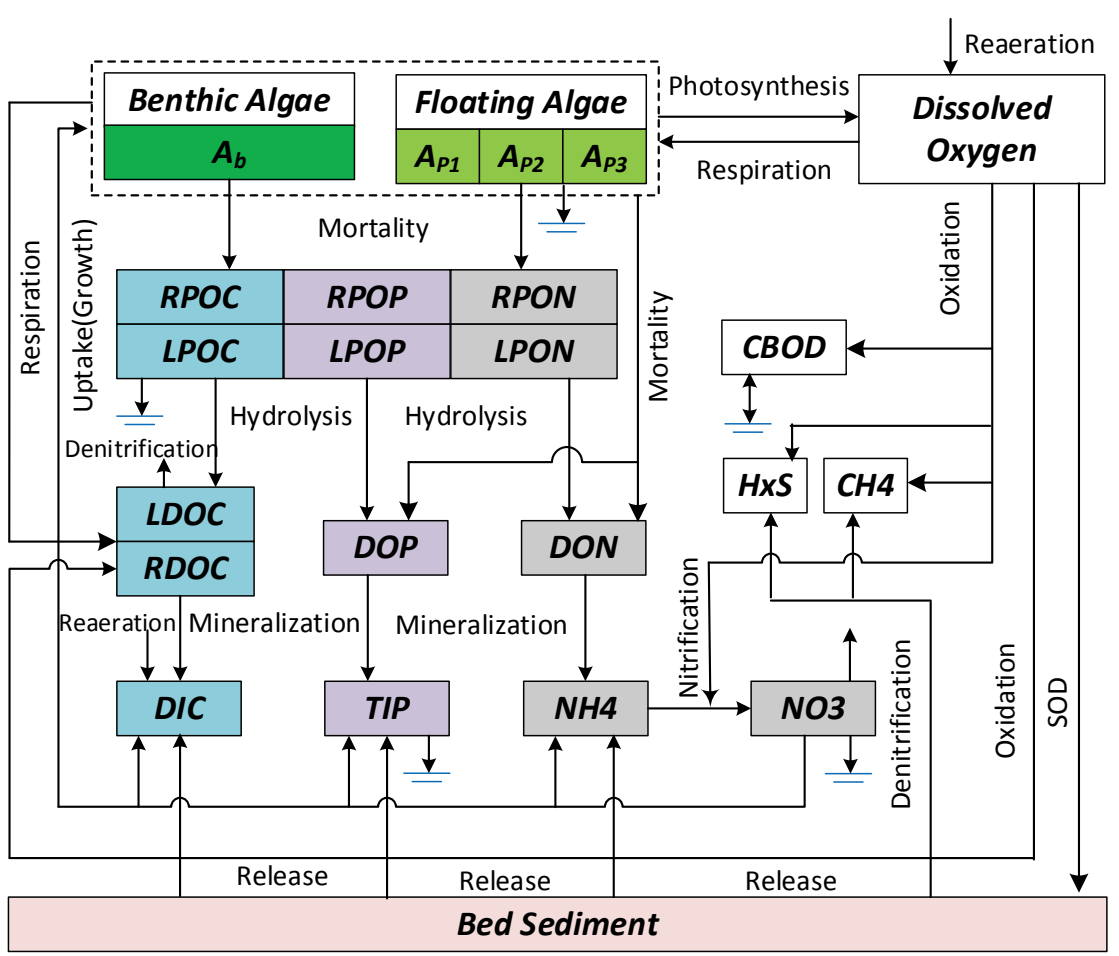

Sediment oxygen demand (SOD), due to the diagenesis of organic materials in bottom sediments, can contribute to oxygen declines in water bodies, such as seasonal declines in hypolimnetic oxygen observed in most reservoirs (Martin et al. 2007). Over lengthy time scales (e.g., years to decades), the benthic sediments are an ultimate sink of nutrients and other substances discharged to the water column. Over lesser time scales (e.g., seasons to years), however, sediment release of previously deposited nutrients can be a net source to the water column (Di Toro et al. 1990, Chapra et al. 2015). Modeling SOD and nutrient releases at the sediment-water interface is fundamental to understanding and mitigating the eutrophication and hypoxia problems in water bodies. Therefore, an optional benthic sediment diagenesis module was included for coupling with the NSMII's water column kinetics. Sediment-water fluxes of dissolved oxygen and nutrients are computed internally rather than prescribed if the benthic sediment diagenesis module is activated.

\subsection{Objective}

A thorough validation and evaluation of the newly developed sediment diagenesis module is essential. The authors were not aware of measurements that allow a direct validation of the results of the benthic sediment diagen- 
esis module. Therefore, the sediment diagenesis module developed for NSMI and NSMII has been verified and evaluated through a series of case studies. In these test cases, sediment diagenesis simulation computed results were compared to similar outputs generated from the sediment diagenesis model including Microsoft Excel SedFlux (Chapra et al. 2008), and CE-QUAL-ICM (Cerco and Cole 1993, Di Toro and Fitzpatrick 1993, Cerco et al. 2004). This report describes the results of the model validation and evaluation studies. The report also provides information about the sediment diagenesis input parameters and model capabilities.

\subsection{Approach}

In this study, intercomparison was carried out between three different water quality models, each with a sediment diagenesis component, including Microsoft Excel SedFlux (Chapra et al. 2008), and CE-QUAL-ICM (Cerco and Cole 1993, Di Toro and Fitzpatrick 1993, Cerco et al. 2004). The intercomparison included a comparison between model results and algorithms. A series of case studies were designed for representing various sedimentation and environmental conditions. Note that validation in this context refers to validation of the model framework, rather than validation of simulation results. Model validation tests were designed to analyze benthic sediment diagenesis processes and estimate sediment-water exchanges of nutrients and oxygen demand. All test case studies were used to verify that the algorithms and formulations are implemented correctly in NSMII. Model testing and validation studies were also used to provide further insight into the sediment-water interactions between the processes regulating the SOD and nutrient release. This report documents testing and evaluation of the NSMII-benthic sediment diagenesis module. 


\section{Benthic Sediment Diagenesis Module}

The NSMs couple the water column kinetics with a two-layer benthic sediment diagenesis module and internally computes sediment-water column fluxes of nutrients and SOD based on deposition of organic particles and other factors. The basic framework of the sediment diagenesis module consists of two well-mixed sediment layers, a thin upper layer (layer 1) and a thicker active layer on the order of $10 \mathrm{~cm}$ (layer 2). The upper layer (layer 1), in contact with the water column, may be oxic or anoxic, depending on DO concentration in the water. The lower layer (layer 2) is always anoxic. The upper layer depth is at its maximum only a small fraction of the active sediment depth $(\sim 0.1 \mathrm{~cm})$. The sediment diagenesis module simulates four basic processes: 1) the deposition of algae and particulate organic matter (POC, PON, POP) as depositional fluxes from the water column directly to the second layer due to the negligible thickness of the upper layer, 2) the diagenesis of the sediment particulate organic matter in the second layer produces soluble substances that are quantified as diagenesis fluxes, 3 ) the solutes react and transfer between two layers or are released as gases, and 4) the solutes are returned to the overlaying water. Figure 2 provides an overview of the state variables and processes simulated in the sediment diagenesis module. Diagenesis (mineralization) reactions occur in the second layer. Organic matter initially mineralizes rapidly in the benthic sediments, but then slows down. In order to capture this process, sediment POC, PON, and POP are fractionated to three "G classes." The basis of the multi-G assumption came from laboratory experiments that showed organic matter decay could be approximated as a function of different pools (Berner 1980). The G1, labile, fraction has a half-life of 20 days. The G2, refractory, fraction has a half-life of one year. The $\mathrm{G}_{3}$, inert, fraction undergoes no significant decay before burial into deep, inactive sediments (Di Toro 2001). 
Figure 2. Schematic overview of the state variables and processes modeled in the benthic sediment diagenesis module.

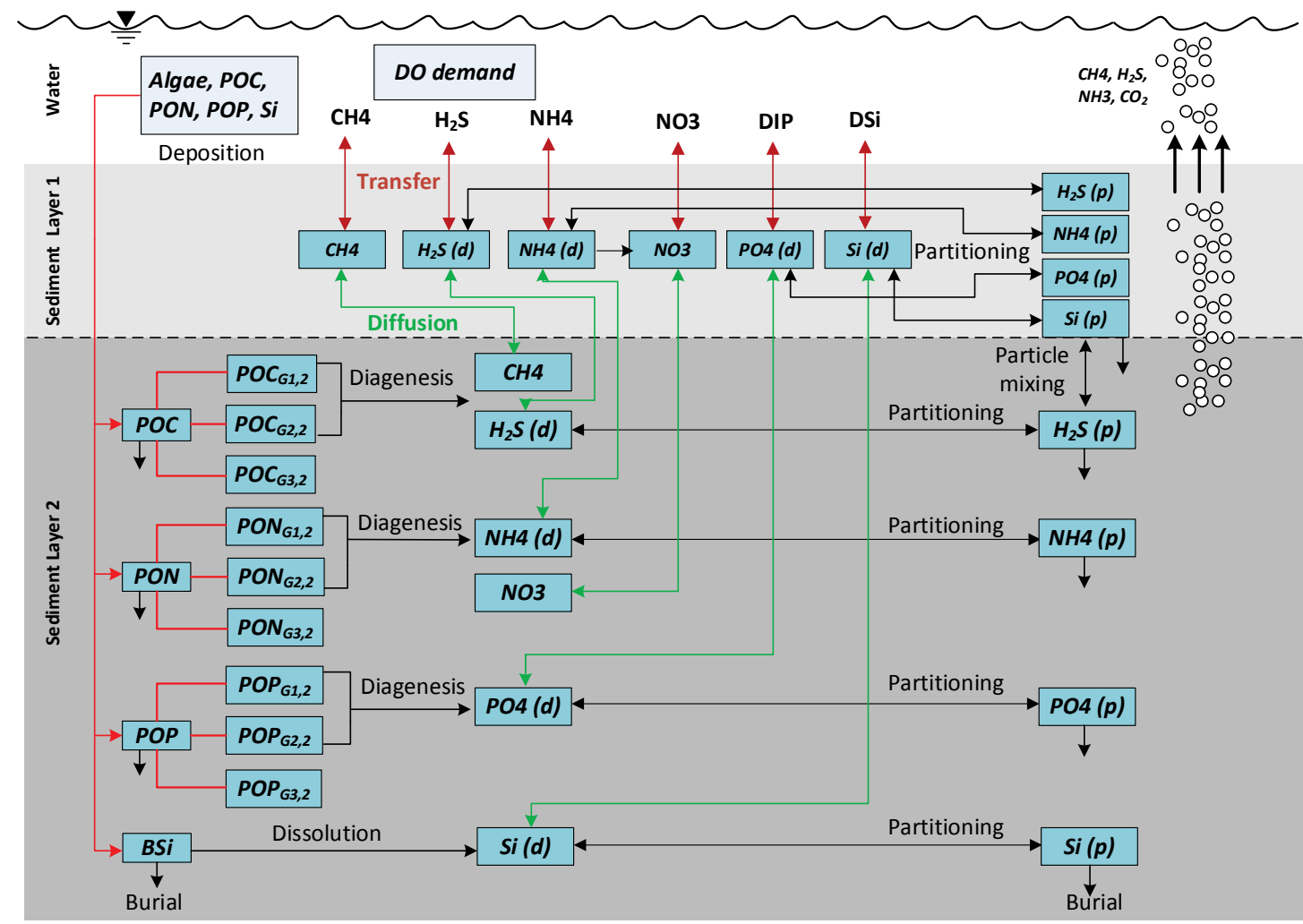

Additionally, 27 sediment diagenesis state variables are included in each NSM module if the sediment diagenesis module is activated. Table 2 lists the sediment diagenesis state variables and the symbols. Three state variables are utilized to represent three reactivity classes (G1 through G3). The units of these variables are grams per sediment layer volume basis, or mg $\mathrm{L}^{-1}$. Methane, sulfate, and sulfide are tracked in units of oxygen equivalents to easily balance the model's computations.

Table 2. Water quality state variables modeled in the NSMII-benthic sediment diagenesis module.

\begin{tabular}{|c|c|c|c|}
\hline Symbol & Variable Name & Bed layer & Units \\
\hline $\mathrm{NH} 4_{1}$ & Sediment ammonium & 1 & mg-N L-1 \\
\hline $\mathrm{NO}_{1}$ & Sediment nitrate-nitrite & 1 & mg-N L-1 \\
\hline $\mathrm{CH}_{1}$ & Sediment methane & 1 & $m g-\mathrm{O}_{2} \mathrm{~L}^{-1}$ \\
\hline $\mathrm{SO}_{1}$ & Sediment sulfate & 1 & $m g-\mathrm{O}_{2} \mathrm{~L}^{-1}$ \\
\hline $\mathrm{TH}_{2} \mathrm{~S}_{1}$ & Sediment total sulfide & 1 & $\mathrm{mg}-\mathrm{O}_{2} \mathrm{~L}^{-1}$ \\
\hline$T I P_{1}$ & Sediment total inorganic phosphorous & 1 & mg-P L-1 \\
\hline$D S i_{1}$ & Sediment dissolved silica & 1 & mg-Si L-1 \\
\hline
\end{tabular}




\begin{tabular}{|c|c|c|c|}
\hline Symbol & Variable Name & Bed layer & Units \\
\hline $\mathrm{NH}_{2}$ & Sediment ammonium & 2 & mg-N L-1 \\
\hline $\mathrm{NO}_{2}$ & Sediment nitrate-nitrite & 2 & mg-N L-1 \\
\hline $\mathrm{CH}_{2}$ & Sediment methane & 2 & $\mathrm{mg}-\mathrm{O}_{2} \mathrm{~L}^{-1}$ \\
\hline $\mathrm{SO}_{2}$ & Sediment sulfate & 2 & $m g-O_{2} L^{-1}$ \\
\hline $\mathrm{TH}_{2} \mathrm{~S}_{2}$ & Sediment total sulfide & 2 & $m g-\mathrm{O}_{2} \mathrm{~L}^{-1}$ \\
\hline $\mathrm{TIP}_{2}$ & Sediment total inorganic phosphorous & 2 & mg-P L-1 \\
\hline$D S i_{2}$ & Sediment dissolved silica & 2 & mg-Si L-1 \\
\hline$P O C_{G i, 2}$ & $\begin{array}{l}\text { Sediment particulate organic carbon (G1 } \\
\text { - G3) }\end{array}$ & 2 & mg-C L-1 \\
\hline$P O N_{G i, 2}$ & $\begin{array}{l}\text { Sediment particulate organic nitrogen } \\
\text { (G1 - G3) }\end{array}$ & 2 & mg-N L-1 \\
\hline$P O P_{G i, 2}$ & $\begin{array}{l}\text { Sediment particulate organic } \\
\text { phosphorous (G1 - G3) }\end{array}$ & 2 & mg-P L-1 \\
\hline $\mathrm{BSi}_{2}$ & Sediment particulate biogenic silica & 2 & mg-Si L-1 \\
\hline ST & Sediment benthic stress & 2 & $d$ \\
\hline
\end{tabular}

The sediment diagenesis module employed here includes two options for its numerical solutions: 1) steady state and 2) unsteady state. Initial conditions are required for the unsteady-state solution for each of the sediment cells below the water column cells. Initial conditions are specified separately for the sediment cells, and differ from those for the water column. Initial conditions are required only for state variables at sediment layer 2 listed above. A detailed discussion of the theory and formulations in the benthic sediment diagenesis module can be found in Zhang and Johnson (2016). 


\section{Testing and Validation Studies}

A comprehensive validation of the benthic sediment diagenesis module would require an extensive and contemporary field measurement of all the variables considered. There would be many difficulties involved with collecting the necessary information. However, some independent checks on the various coefficients and formulations are desirable. Thus, a set of model testing cases were designed to investigate, primarily, the model performance. The sediment diagenesis module was calibrated and validated against experimental data (Martin 2002) and the Chesapeake Bay dataset from 1991 to 2000 through a series of case studies. Since the benthic sediment diagenesis module is based upon the same framework as Microsoft Excel SedFlux (called SedFlux henceforth) and CE-QUAL-ICM (called ICM henceforth), model results from SedFlux and ICM were used in the following model validation studies. The SedFlux is a standalone model of simulating SOD and sediment-water fluxes of nutrients. The subroutine used in SedFlux was adapted from original work for the QUAL2K model (Chapra et al. 2008). SedFlux simulates the production and oxidation of sulfide instead of methane during sediment diagenesis in brackish, estuarine, or marine environments where sufficient sulfate is present. SedFlux includes a steady-state mode and a time variable (unsteady) mode. The ICM's sediment diagenesis model was originally developed as a standalone code and then incorporated into the ICM model (Di Toro and Fitzpatrick 1993) for the Chesapeake Bay application. This sediment diagenesis module was further modified to update methanogenesis-sulfate reduction reactions (Cerco et al. 2004). There are major differences in the model codes relating to the computation of SOD and methane for the three models. The ICM model includes methane and sulfides in the computation of SOD, but differs in the implementation of the sulfide/methane reactions. In SedFlux, sulfide is computed for the saltwater case, while methane is computed for the freshwater case. Sulfides, sulfate, and methane are computed in the ICM and NSMII for both conditions, with a regression equation used to estimate sulfates based upon salinity. In SedFlux, sediment methane concentration is only computed using a steady-state solution for the aerobic layer. Silica is modeled in the sediment diagenesis module, but is not included in these testing and validation studies. 
A testing and validation study was conducted using the Chesapeake Bay water quality datasets through comparing simulation results generated by the NSMII, with model results generated with SedFlux and ICM. The three models were run with, to the extent possible, a consistent set of kinetic coefficients and parameters, initial conditions, deposition fluxes from the water column and water column concentrations in all test cases. In particular, NSMII and SedFlux sediment diagenesis parameters and coefficients for the model comparison were adopted from a calibrated ICM model application to the Chesapeake Bay. The NSMII-benthic sediment diagenesis module was further tested and validated through several special cases and a sensitivity analysis.

\subsection{Model development and result comparisons}

In this test case, an equivalent water column and benthic sediment segment was set up for SedFlux, ICM and NSMII. The sediment diagenesis computational time step was set equal to the water quality model time step. Model predictions by the NSMII were compared against model results generated from SedFlux and ICM using the 1991-2000 Chesapeake Bay dataset. The Chesapeake Bay dataset was used to test and validate the performances of the NSMII predictions with respect to various aspects such as sediment layer organic and inorganic concentrations, SOD, and sediment-water transfer fluxes of inorganic nutrients.

\subsubsection{Input data and model development}

A computational water quality cell with the same force conditions was used to develop three models. Forcing conditions included the sediment deposition rate, a determinant of sediment organic matter supply and the sediment concentration, and thus the driver for diagenesis. Solids concentrations in sediment layers 1 and 2 were set to equal $0.5 \mathrm{~kg} \mathrm{~L}^{-1}$. Thickness of active sediments was equal to $10 \mathrm{~cm}$. Specified initial concentrations of sediment diagenesis state variables are given in Table 3.

Table 3. Initial conditions of benthic sediment diagenesis state variables.

\begin{tabular}{|l|l|l|l|}
\hline \multicolumn{1}{|c|}{ Symbol } & \multicolumn{1}{c|}{ Bed layer } & \multicolumn{1}{c|}{ Units } & \multicolumn{1}{c|}{ Values } \\
\hline $\mathrm{NH}_{2}$ & 2 & $\mathrm{mg}-\mathrm{N} \mathrm{L}^{-1}$ & 7.76 \\
\hline $\mathrm{NO}_{2}$ & 2 & $\mathrm{mg}-\mathrm{N} \mathrm{L}^{-1}$ & 0.07 \\
\hline $\mathrm{CH}_{2}$ & 2 & $\mathrm{mg}-\mathrm{O}_{2} \mathrm{~L}^{-1}$ & 0.02 \\
\hline $\mathrm{SO}_{2}$ & 2 & $\mathrm{mg}-\mathrm{O}_{2} \mathrm{~L}^{-1}$ & 1031.67 \\
\hline
\end{tabular}




\begin{tabular}{|c|c|c|c|}
\hline Symbol & Bed layer & Units & Values \\
\hline $\mathrm{TH}_{2} \mathrm{~S}_{2}$ & 2 & $m g-O_{2} L^{-1}$ & 3590.40 \\
\hline$T I P_{2}$ & 2 & mg-P L-1 & 112.47 \\
\hline$P O C_{G 1,2}$ & 2 & mg-C L-1 & 56.23 \\
\hline$P O C_{\mathrm{G} 2,2}$ & 2 & mg-C L-1 & 1072.33 \\
\hline$P O C_{G 3,2}$ & 2 & mg-C L-1 & 24966.55 \\
\hline$P O N_{G 1,2}$ & 2 & mg-N L-1 & 10.87 \\
\hline$P O N_{\mathrm{G} 2,2}$ & 2 & mg-N L-1 & 208.34 \\
\hline$P O N_{\mathrm{G} 3,2}$ & 2 & mg-N L-1 & 3114.92 \\
\hline$P O P_{\mathrm{G} 1,2}$ & 2 & mg-P L-1 & 0.83 \\
\hline$P O P_{\mathrm{G} 2,2}$ & 2 & mg-P L-1 & 9.25 \\
\hline$P O P_{\mathrm{G} 3,2}$ & 2 & mg-P L-1 & 98.30 \\
\hline ST & 2 & $d$ & 22.55 \\
\hline
\end{tabular}

The NSMII computes time-varying concentrations in a water column overlying the sediment bed. In order to identify differences in the time-variable nature of model predictions for the three models, The Chesapeake Bay dataset used in the ICM model inputs were read into both the NSMII and SedFlux. This test case ensured that all three models used the same forcing functions for deriving the bed sediment diagenesis processes. Depositional rates of water column organic matter to the benthic sediments are given as model inputs and shown in Figure 3.

Figure 3. Time series plots of water column depositional rates:

(a) POC, (b) PON, and (c) POP.

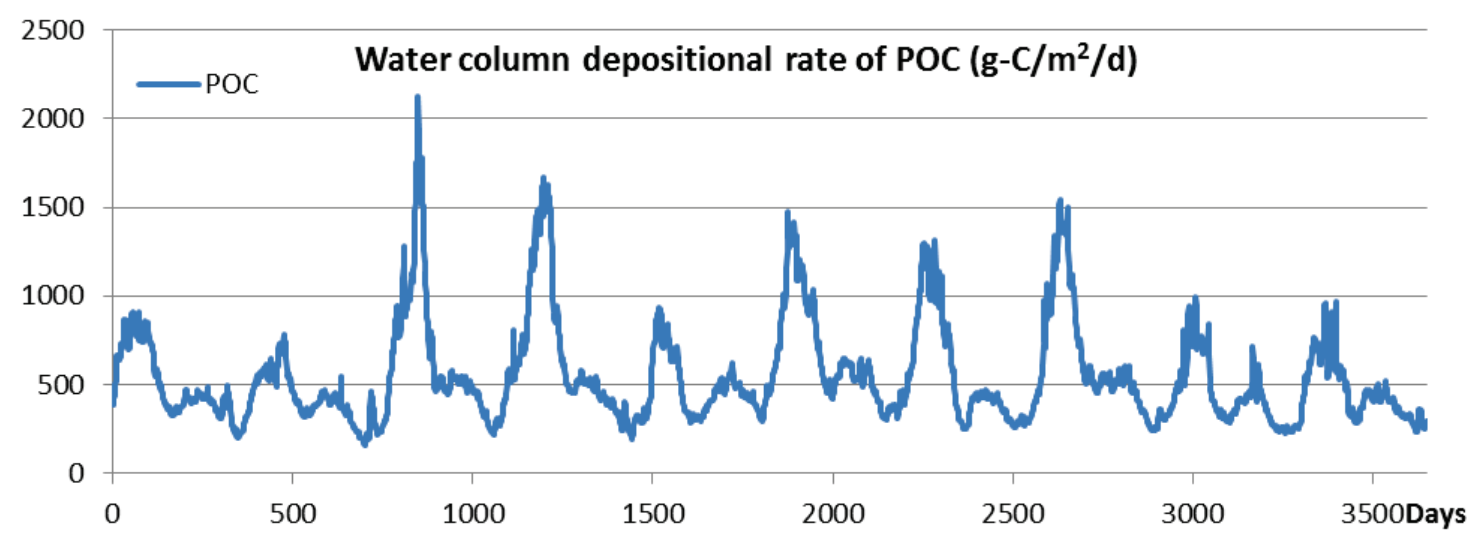




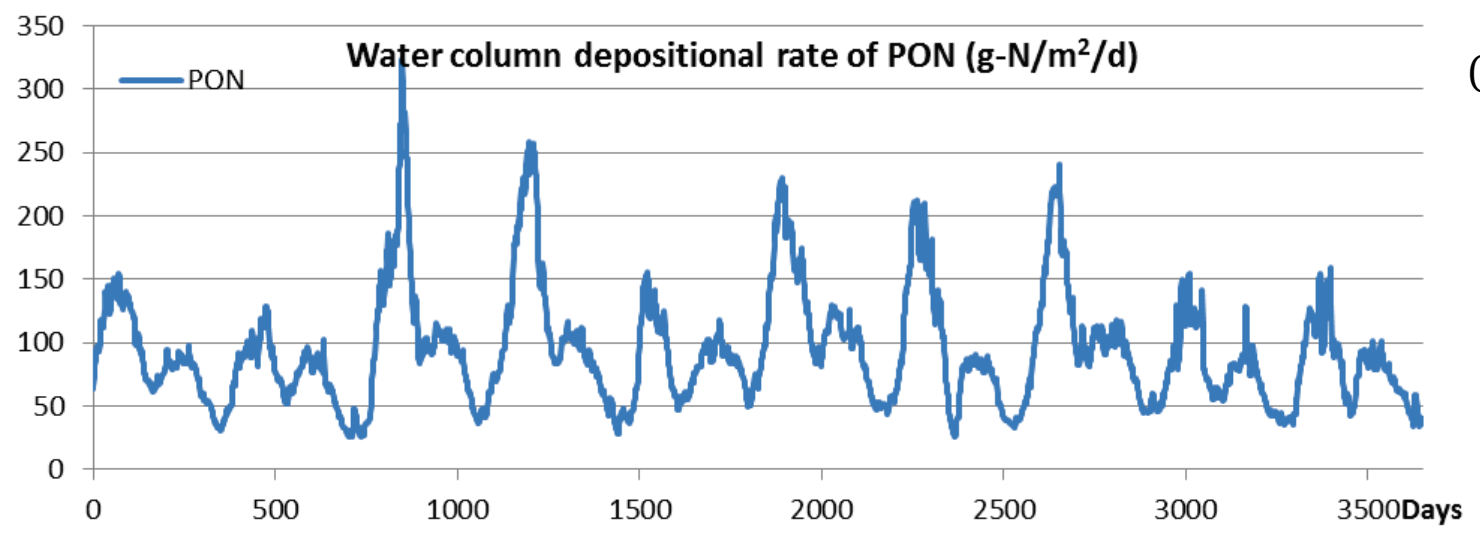

(b)

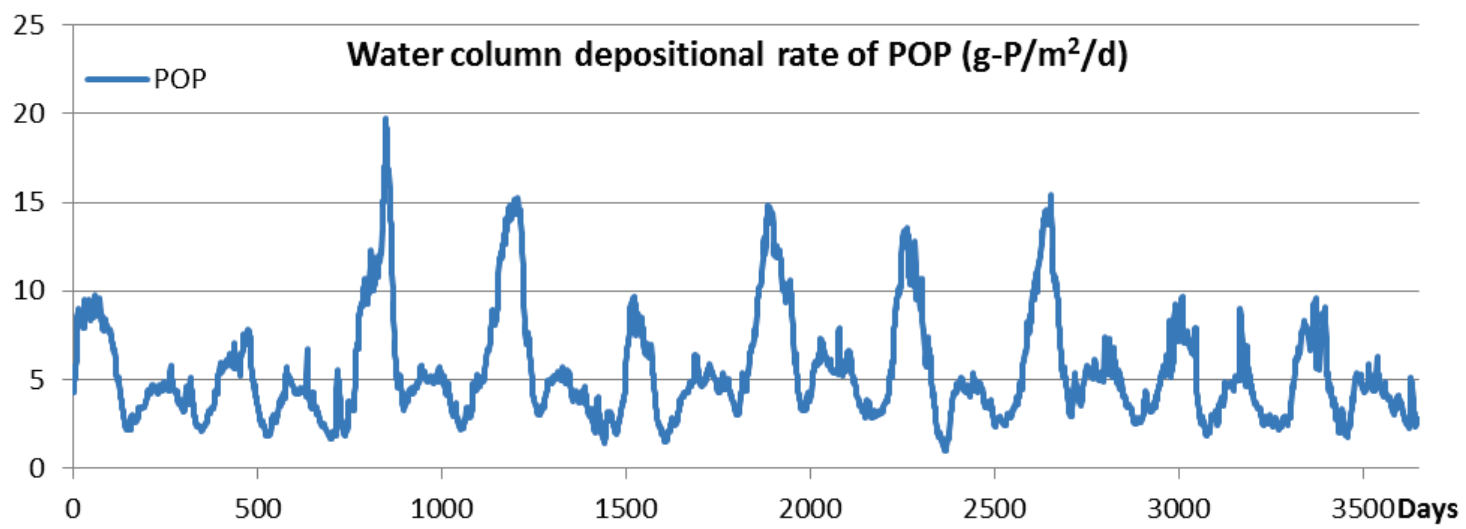

(c)

Water column concentrations of ammonia ( $\mathrm{NH}_{4}$ ), nitrate (NO3), dissolved inorganic phosphorous (DIP), and dissolved oxygen (DO) are shown in Figure 4. DO time series exhibit summer peaks at this location where overlying-water DO levels remain above $10 \mathrm{mg} / \mathrm{L}$ for the majority of the year.

Figure 4. Time series plots of the water column concentrations:

(a) NH4, (b) NO3, (c) DIP, and (d) DO.

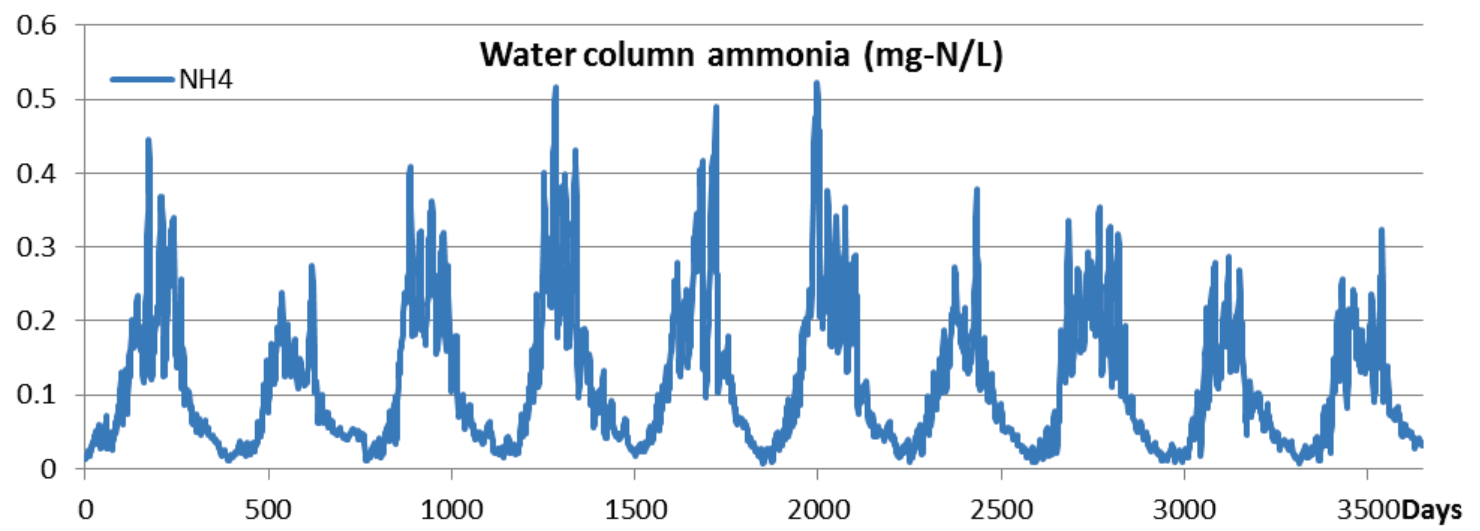



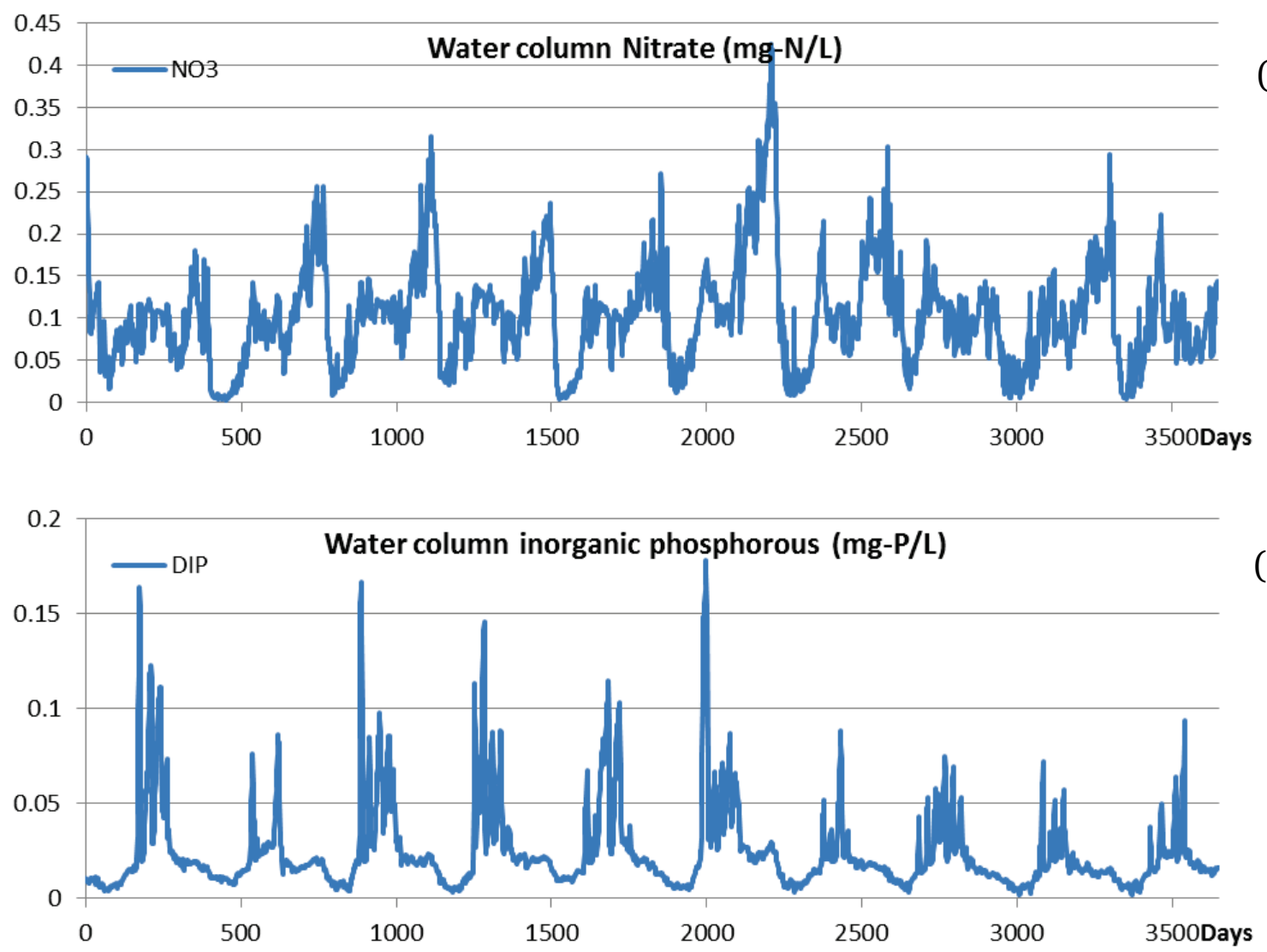

(c)

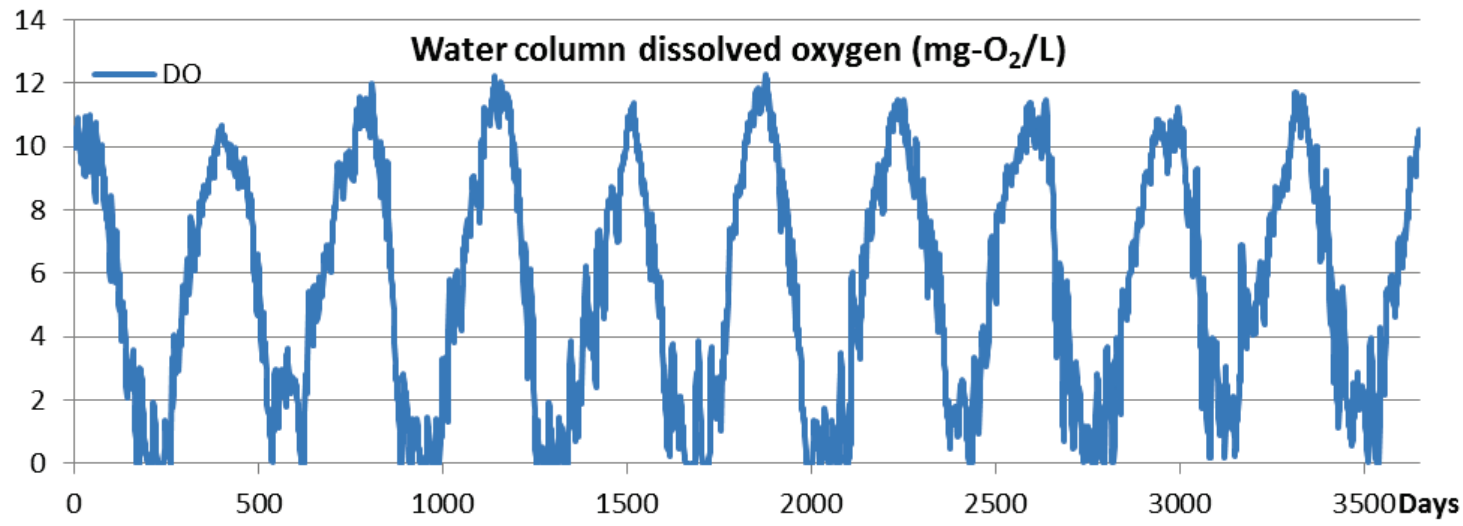

Unsteady-state SedFlux, NSMII and ICM models were run with the conditions specified above and results compared. Each model was run for a period of 1000 days. Table 4 presents the final values of the sediment diagenesis process parameters and coefficients used in the three models. 
Table 4. Key sediment diagenesis module input parameters and coefficients.

\begin{tabular}{|c|c|c|c|c|c|c|}
\hline Symbol & Parameter & $\begin{array}{l}\text { Bed } \\
\text { layer }\end{array}$ & Unit & Value & & $\begin{array}{l}\text { perature } \\
\text { jendent }\end{array}$ \\
\hline$D O_{c}$ & Layer 1 critical $\mathrm{O}_{2}$ for incremental sorption & 1 & $\mathrm{mg}-\mathrm{O}_{2} \mathrm{~L}^{-1}$ & 2.0 & & \\
\hline$\Delta K_{P 041}$ & $\begin{array}{l}\text { Layer } 1 \text { increamental inorganic } P \text { partition } \\
\text { coefficient }\end{array}$ & 1 & unitless & 300 & & \\
\hline$V_{c h 4,1}(T)$ & Layer $1 \mathrm{CH} 4$ oxidation transfer velocity & 1 & $m d^{-1}$ & 0.2 & Yes & 1.079 \\
\hline$V_{h 2 s, d}(T)$ & $\begin{array}{l}\text { Layer } 1 \text { dissolved } \mathrm{H}_{2} \mathrm{~S} \text { oxidation transfer } \\
\text { velocity }\end{array}$ & 1 & $m$ day $^{-1}$ & 0.2 & Yes & 1.079 \\
\hline$V_{h 2 s, p}(T)$ & $\begin{array}{l}\text { Layer } 1 \text { particulate } \mathrm{H}_{2} \mathrm{~S} \text { oxidation transfer } \\
\text { velocity }\end{array}$ & 1 & $m$ day $^{-1}$ & 0.4 & Yes & 1.079 \\
\hline$k_{s H 2 S}$ & $\begin{array}{l}\text { Layer } 1 \mathrm{H}_{2} \mathrm{~S} \text { oxidation normalization } \\
\text { constant }\end{array}$ & 1 & $m g-O_{2} L^{-1}$ & 4.0 & & \\
\hline Ksoxch & $\begin{array}{l}\text { Layer } 1 \text { half-saturation oxygen constant } \\
\text { for } \mathrm{CH} 4 \text { oxidation }\end{array}$ & 1 & $\mathrm{mg}-\mathrm{O}_{2} \mathrm{~L}^{-1}$ & 0.2 & & \\
\hline$V_{n h 4,1}(T)$ & Layer 1 nitrification transfer velocity & 1 & $\mathrm{~m} \mathrm{~d}^{-1}$ & 0.14 & Yes & 1.08 \\
\hline$K_{\text {soxna1 }}$ & $\begin{array}{l}\text { Layer } 1 \text { half-saturation oxygen constant } \\
\text { for nitrification }\end{array}$ & 1 & $m g-O_{2} L^{-1}$ & 0.37 & & \\
\hline$K_{s N h 4}$ & $\begin{array}{l}\text { Layer } 1 \text { half-saturation } \mathrm{NH} 4 \text { constant for } \\
\text { nitrification }\end{array}$ & 1 & mg-N L-1 & 0.728 & & \\
\hline$V_{n \circ 3,1}(T)$ & Layer 1 denitrification transfer velocity & 1 & $\mathrm{~m} \mathrm{~d}^{-1}$ & 0.125 & Yes & 1.08 \\
\hline$C_{s s}$ & Layer 1 solid concentration & 1 & $k g L^{-1}$ & 0.5 & & \\
\hline$F_{A P 1}$ & Fraction of algae settling into G1 class & 2 & unitless & 0.6 & & \\
\hline$F_{A P 2}$ & Fraction of algae settling into G2 class & 2 & unitless & 0.2 & & \\
\hline$F_{R P O C 1}$ & $\begin{array}{l}\text { Fraction of RPOC settling into sediment } \\
\text { POC G1 }\end{array}$ & 2 & unitless & 0.15 & & \\
\hline$F_{R P O C 2}$ & $\begin{array}{l}\text { Fraction of RPOC settling into sediment } \\
\text { POC G2 }\end{array}$ & 2 & unitless & 0.35 & & \\
\hline$F_{R P O N 1}$ & $\begin{array}{l}\text { Fraction of RPON settling into sediment } \\
\text { PON G1 }\end{array}$ & 2 & unitless & 0.15 & & \\
\hline$F_{R P O N 2}$ & $\begin{array}{l}\text { Fraction of RPON settling into sediment } \\
\text { PON G2 }\end{array}$ & 2 & unitless & 0.35 & & \\
\hline$F_{R P O P 1}$ & $\begin{array}{l}\text { Fraction of RPOP settling into sediment } \\
\text { POP G1 }\end{array}$ & 2 & unitless & 0.15 & & \\
\hline$F_{R P O P 2}$ & $\begin{array}{l}\text { Fraction of RPOP settling into sediment } \\
\text { POP G2 }\end{array}$ & 2 & unitless & 0.35 & & \\
\hline$K_{P O C G 1}(T)$ & Diagenesis rate of sediment POC G1 & 2 & $d^{-1}$ & 0.035 & Yes & 1.1 \\
\hline$K_{P O C G 2}(T)$ & Diagnesis rate of sediment POC G2 & 2 & $d^{-1}$ & 0.0018 & Yes & 1.15 \\
\hline$K_{P O N G 1}(T)$ & Diagenesis rate of sediment PON G1 & 2 & $d^{-1}$ & 0.035 & Yes & 1.1 \\
\hline$K_{P O N G 2}(T)$ & Diagenesis rate of sediment PON G2 & 2 & $d^{-1}$ & 0.0018 & Yes & 1.15 \\
\hline
\end{tabular}




\begin{tabular}{|c|c|c|c|c|c|c|}
\hline Symbol & Parameter & $\begin{array}{c}\text { Bed } \\
\text { layer }\end{array}$ & Unit & Value & & $\begin{array}{l}\text { perature } \\
\text { pendent }\end{array}$ \\
\hline$K_{P O P G 1}(T)$ & Diagenesis rate of sediment POP G1 & 2 & $d^{-1}$ & 0.035 & Yes & 1.1 \\
\hline$K_{P O P G 2}(T)$ & Diagenesis rate of sediment POP G2 & 2 & $d^{-1}$ & 0.0018 & Yes & 1.15 \\
\hline$k_{d n h 42}$ & Layer $2 \mathrm{NH} 4$ partition coefficient & 2 & $\mathrm{~L} \mathrm{~kg}^{-1}$ & 1.0 & & \\
\hline$k_{d h 2 s 2}$ & Layer $2 \mathrm{H}_{2} \mathrm{~S}$ partition coefficient & 2 & $\mathrm{~L} \mathrm{~kg}^{-1}$ & 100 & & \\
\hline$V_{n 03,2}(T)$ & Layer 2 denitrification transfer velocity & 2 & $\mathrm{~m} \mathrm{~d}^{-1}$ & 0.25 & Yes & 1.08 \\
\hline$k_{d p 042}$ & Layer 2 inorganic $P$ partition coefficient & 2 & $\mathrm{~L} \mathrm{~kg}^{-1}$ & 100 & & \\
\hline$k_{s t}$ & Decay rate of sediment benthic stress & 2 & $d^{-1}$ & 0.03 & & \\
\hline$K_{\text {sSO4 }}$ & $\begin{array}{l}\text { Layer } 2 \mathrm{SO} 4 \text { half-saturation constant for } \\
\text { reduction }\end{array}$ & 2 & $m g-\mathrm{O}_{2} \mathrm{~L}^{-1}$ & 1.08 & & \\
\hline$C_{s s}$ & Layer 2 solid concentration & 2 & $\mathrm{~kg} \mathrm{L-1}$ & 0.5 & & \\
\hline$W_{2}$ & Sedimentation burial velocity & 2 & $m d^{-1}$ & $\begin{array}{l}4.93 E- \\
05\end{array}$ & & \\
\hline$D d(T)$ & Sediment pore-water diffusion coefficient & & $m^{2} d^{-1}$ & 0.0005 & Yes & 1.08 \\
\hline$D p(T)$ & $\begin{array}{l}\text { Sediment particle mixing diffusion } \\
\text { coefficient }\end{array}$ & & $m^{2} d^{-1}$ & 0.00003 & Yes & 1.117 \\
\hline$K_{\mathrm{sDp}}$ & $\begin{array}{l}\text { Half-saturation oxygen constant for } \\
\text { sediment particle phase mixing }\end{array}$ & & $m g-\mathrm{O}_{2} \mathrm{~L}^{-1}$ & 4.0 & & \\
\hline$P O C_{r}$ & Reference sediment POC for bioturbation & & mg-C g-1 & 0.1 & & \\
\hline
\end{tabular}

\subsubsection{Predictions of sediment organic matter diagenesis fluxes}

Sediment organic matter diagenesis processes are modeled by partitioning the settling organic matter into three reactivity classes (3G). Each class represents a fixed portion of the organic material that reacts at a specific rate. Diagenesis of particulate organic carbon (POC), particulate organic nitrogen (PON), and phosphorous (P) is computed from a mass balance equation. Model predictions for sediment diagenesis fluxes, e.g., carbon $\left(\mathrm{J}_{\mathrm{Cc}}\right)$, nitrogen $\left(\mathrm{J}_{\mathrm{N}}\right)$, and phosphorous $\left(\mathrm{J}_{\mathrm{P}}\right)$, are shown in Figure 5 . The three models (SedFlux, ICM, and NSMII) produced identical results as expected because the same water quality deposition inputs and diagenesis rates were applied in the three models. 
Figure 5. Comparisons of model predictions of the sediment total diagenesis fluxes:

(a) carbon, (b) nitrogen, (c) phosphorous.

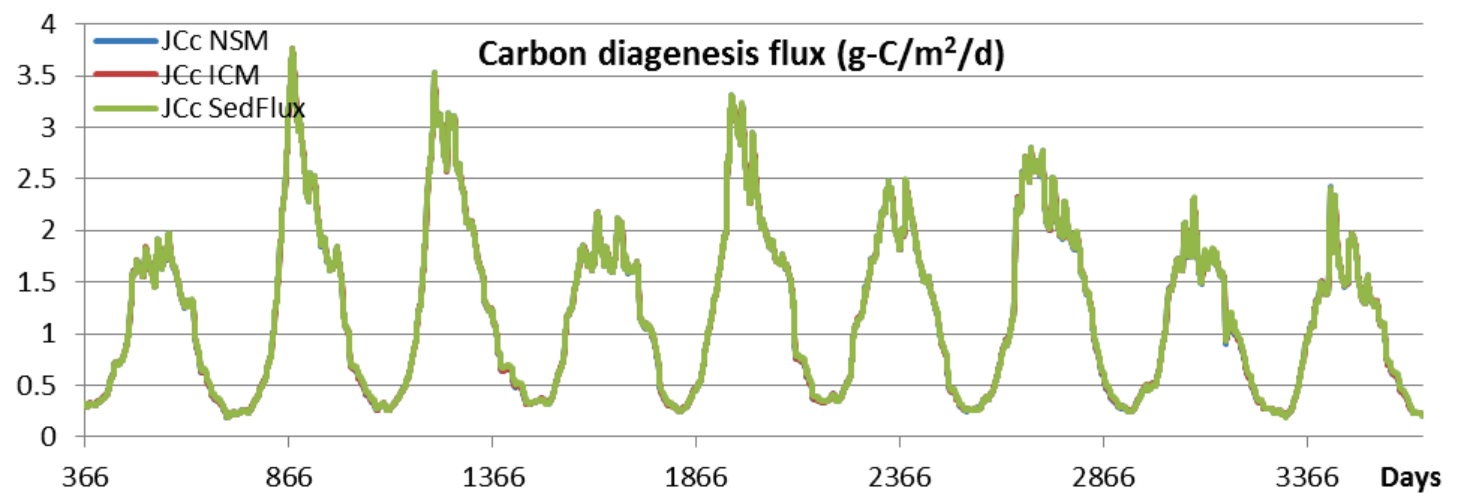

(a)

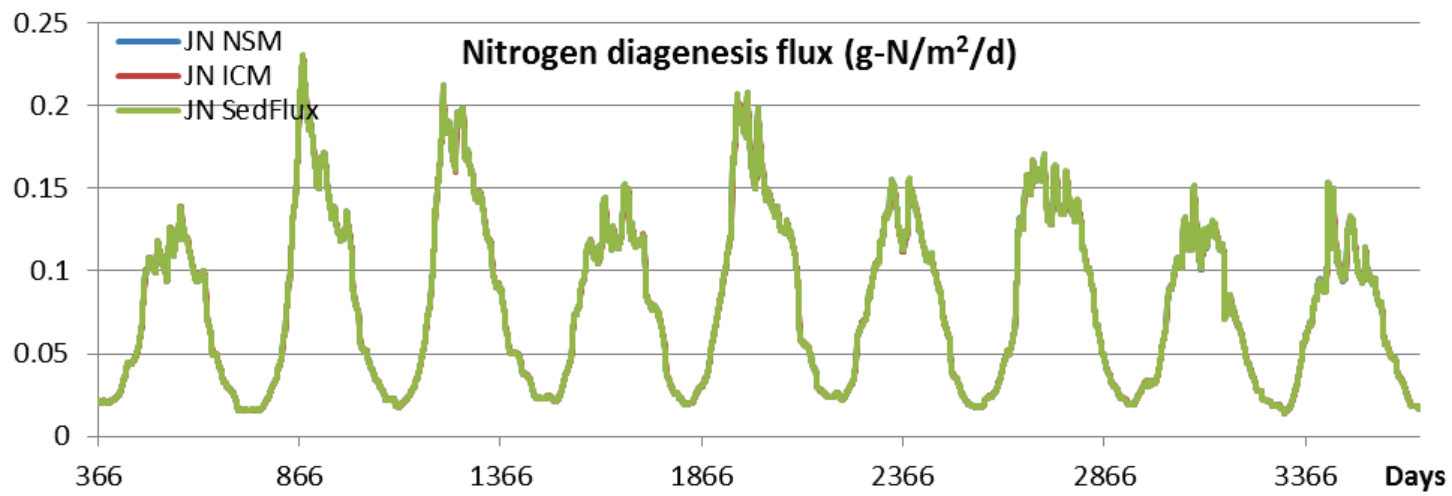

(b)

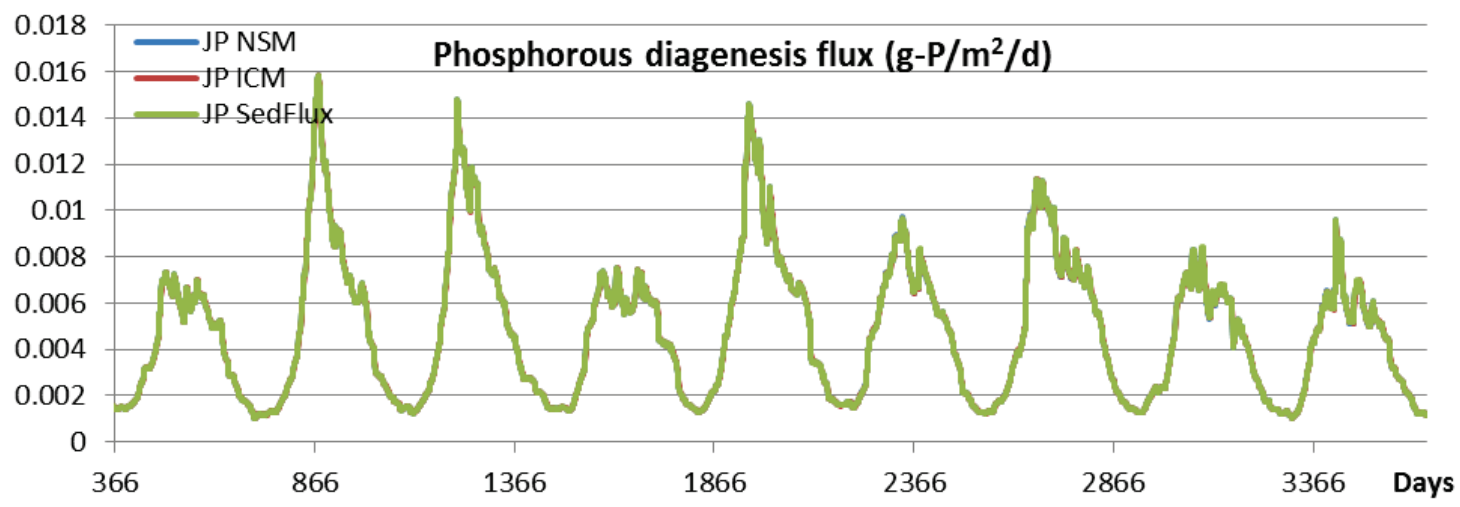

(c)

\subsubsection{Predictions of sediment reaction and transfer coefficients}

Dissolved $\left(\mathrm{K}_{\mathrm{L} 12}\right)$ and particle $\left(\mathrm{w}_{12}\right)$ mixing between layers 1 and 2 are modeled as a function of passive transport and proxies for the activities of benthic organisms. The rate of mixing of sediment particles $\left(\mathrm{w}_{12}\right)$ is quantified by estimating the apparent particle diffusion coefficient. Dissolved species are transported through the two sediment layers by diffusion $\left(\mathrm{K}_{\mathrm{L} 12}\right)$. The sediment-water mass transfer coefficient $\left(\mathrm{K}_{\mathrm{L} 01}\right)$ controls solute exchange between the aerobic layer and the overlying water column. All three parameters depend on the thickness of the active sediment layer and are internally calculated in the NSMII. 
Model predictions for the particle mixing coefficient ( $\mathrm{w}_{12}$ ), diffusion coefficient $\left(\mathrm{K}_{\mathrm{L} 12}\right)$, sediment-water transfer coefficient $\left(\mathrm{K}_{\mathrm{L} 01}\right)$, and benthic stress $(\mathrm{ST})$ are shown in Figure 5. The three models (SedFlux, ICM, and NSMII) produced the identical $\mathrm{K}_{\mathrm{L} 12}$ as expected because the same formulation is implemented. Values of $\mathrm{w}_{12}, \mathrm{~K}_{\mathrm{L} 01}$, and ST computed from the ICM and NSMII are approximately the same. The modeled values varied slightly between the NSMII and SedFlux. This is because the sediment-water transfer and benthic stress are computed by the SedFlux differently from the other two models. In the SedFlux, either methane or sulfide is used to compute carbonaceous oxygen demand (CSOD), which is less than the CSOD computed from the ICM and NSMII. The smaller SOD causes a smaller sediment-water transfer coefficient shown in Figure 6(c). The temperature correction on the benthic stress is not included in the SedFlux.

Figure 6. Comparisons of model predictions of (a) particle mixing coefficient ( $\left.w_{12}\right),(b)$ diffusion coefficient ( $\left.K_{\mathrm{L} 12}\right)$, (c) sediment-water transfer coefficient $\left(K_{\mathrm{LO1}}\right)$, and (d) sediment stress (ST).

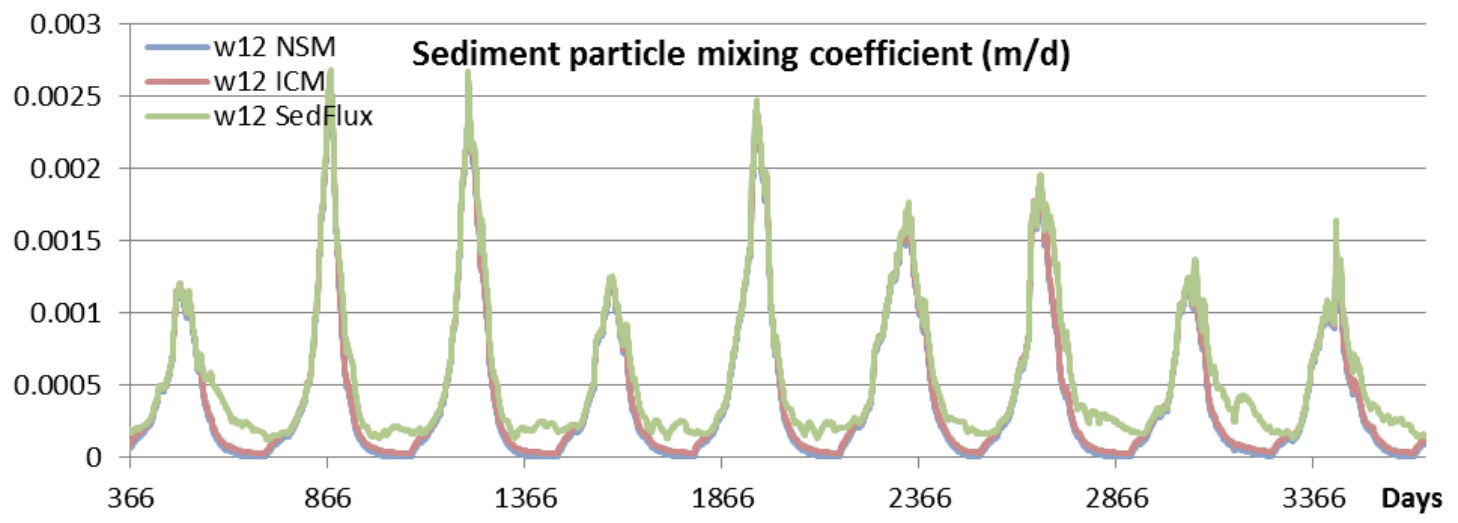

(a)

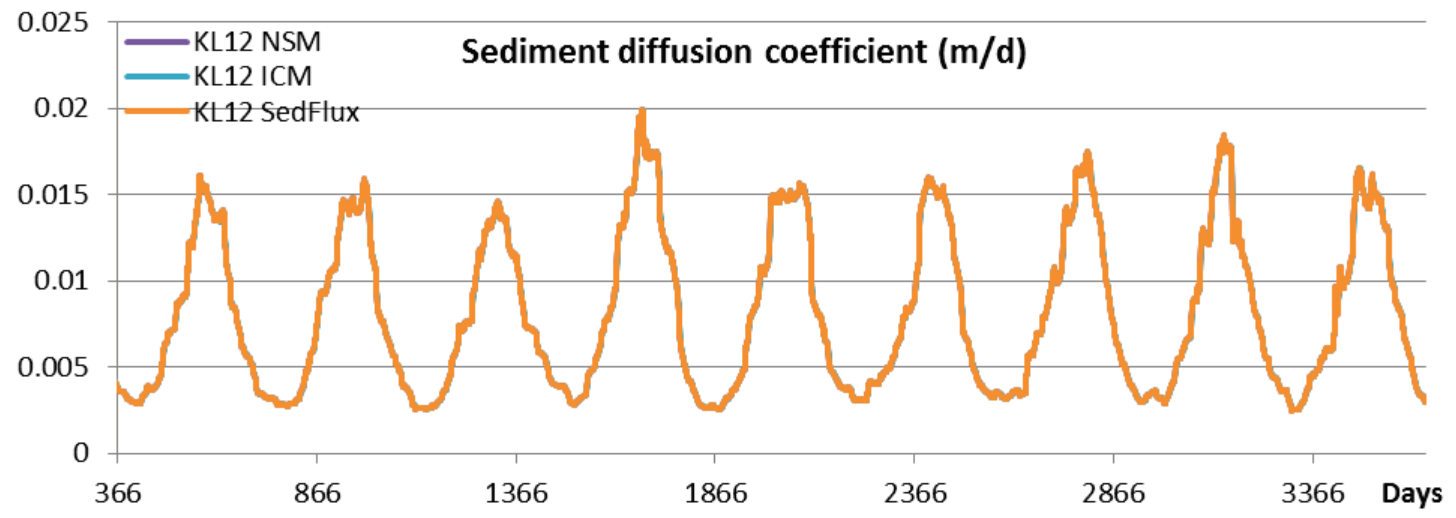

(b) 

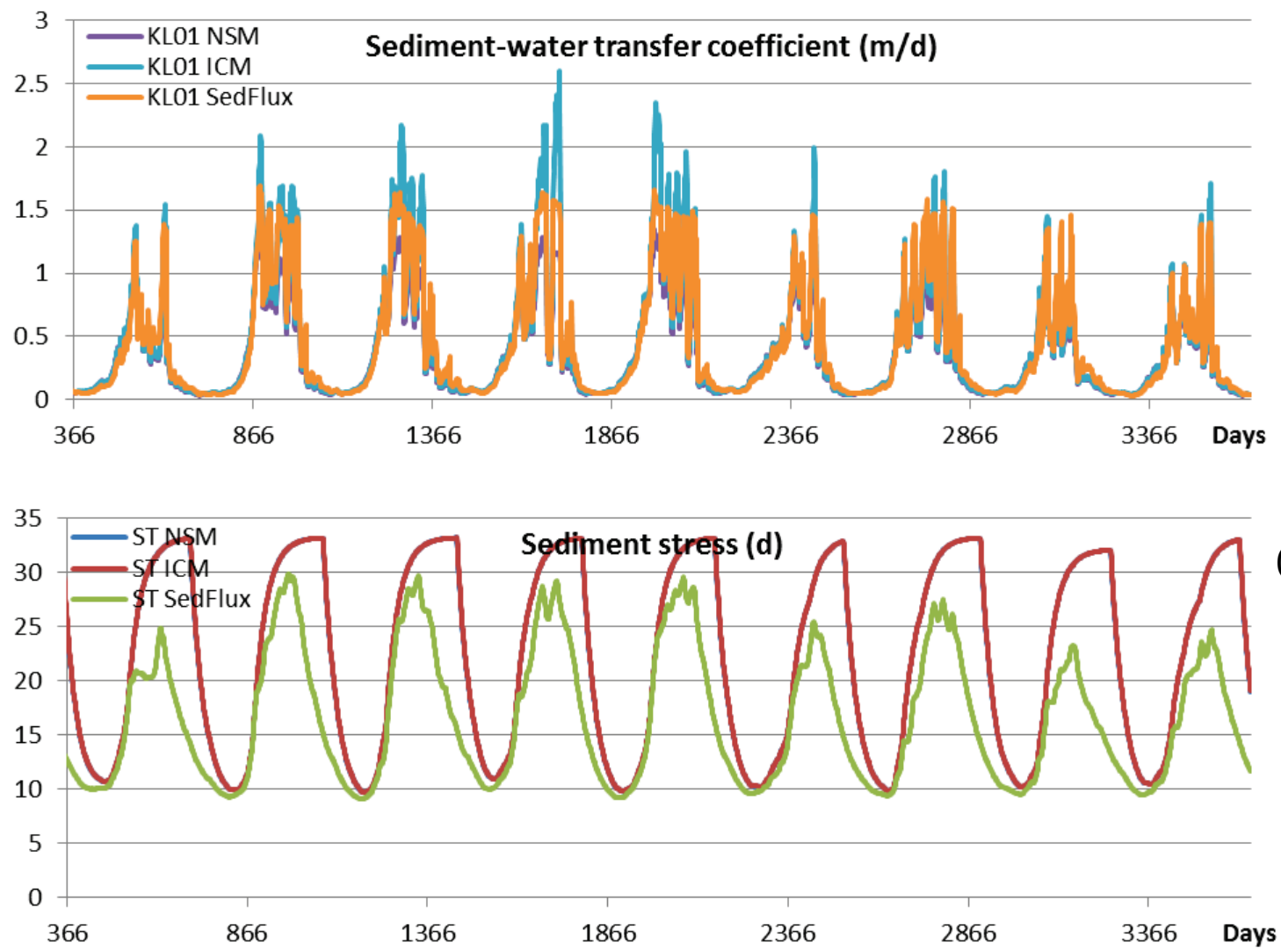

\subsubsection{Predictions of sediment concentrations of inorganic constituents}

Sediment concentrations of ammonia ( $\mathrm{NH}_{4}$ ), nitrate (NO3), total inorganic phosphorous (TIP), sulfide $\left(\mathrm{TH}_{2} \mathrm{~S}\right)$, and methane $\left(\mathrm{CH}_{4}\right)$ are computed for both aerobic and anaerobic layers via mass balances of biogeochemical and physical processes. Model predictions for sediment $\mathrm{NH}_{4}, \mathrm{NO}_{3}$, TIP, $\mathrm{TH}_{2} \mathrm{~S}$, and $\mathrm{CH}_{4}$ in layers 2 and 1 are shown in Figure 7 and Figure 8, respectively. Because the same sediment diagenesis fluxes were produced as shown in Figure 5, the three models (SedFlux, ICM, and NSMII) produced approximately the same sediment concentrations except sulfide and methane. In the SedFlux, sulfide is computed for the saltwater case, while methane is computed for the freshwater case. In the ICM and NSMII, sulfate, sulfide, and methane are computed for both conditions. Sediment sulfate is included as a state variable in the ICM and NSMII. Sulfate is produced in the aerobic layer as a result of particulate and dissolved sulfide oxidation and removed in the anaerobic layer via sulfate reduction. Sulfate limitation on sulfide production (via sulfate reduction) is modeled. Methanogenesis is computed as a fraction of total carbon diagenesis, which is also controlled by anaerobic layer sulfate. Methanogenesis is 
equal to total carbon diagenesis when anaerobic layer sulfate is extremely low relative to the half-saturation constant. Therefore, sediment sulfide and methane predicted by the SedFlux are different from the results computed by the other two models.

Figure 7. Comparisons of model predictions of the sediment layer 2's concentrations: (a) NH4, (b) NO3, (c) TIP, (d) $\mathrm{H}_{2} \mathrm{~S}$, and (e) $\mathrm{CH} 4$.

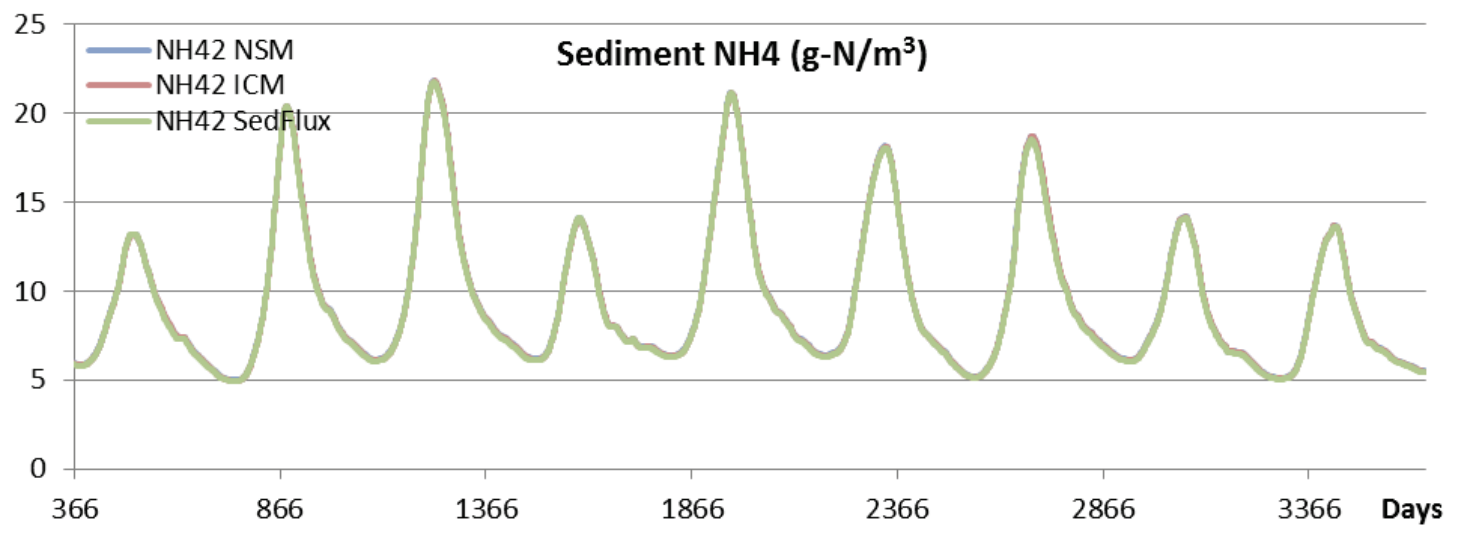

(a)

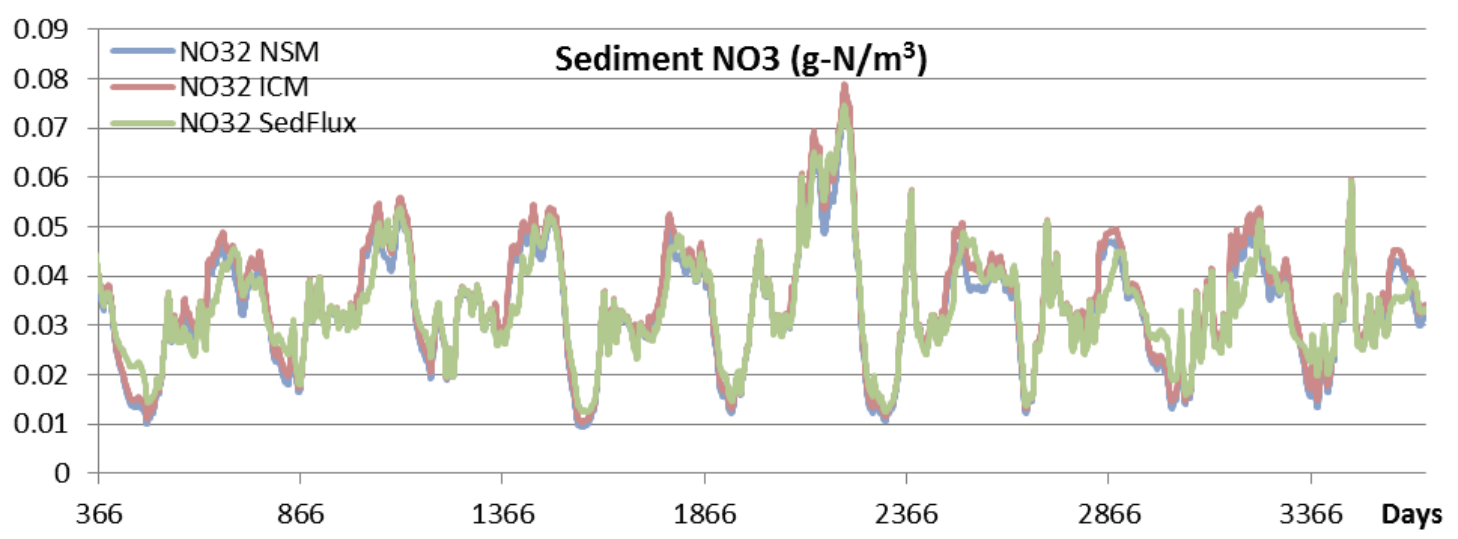

(b)

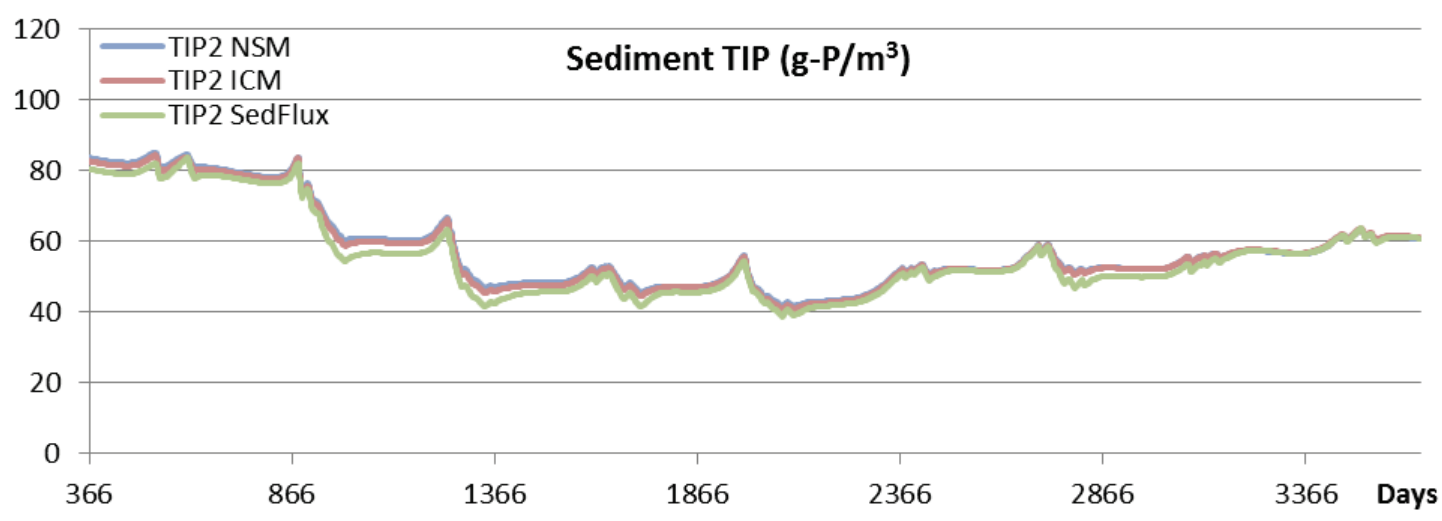

(c) 

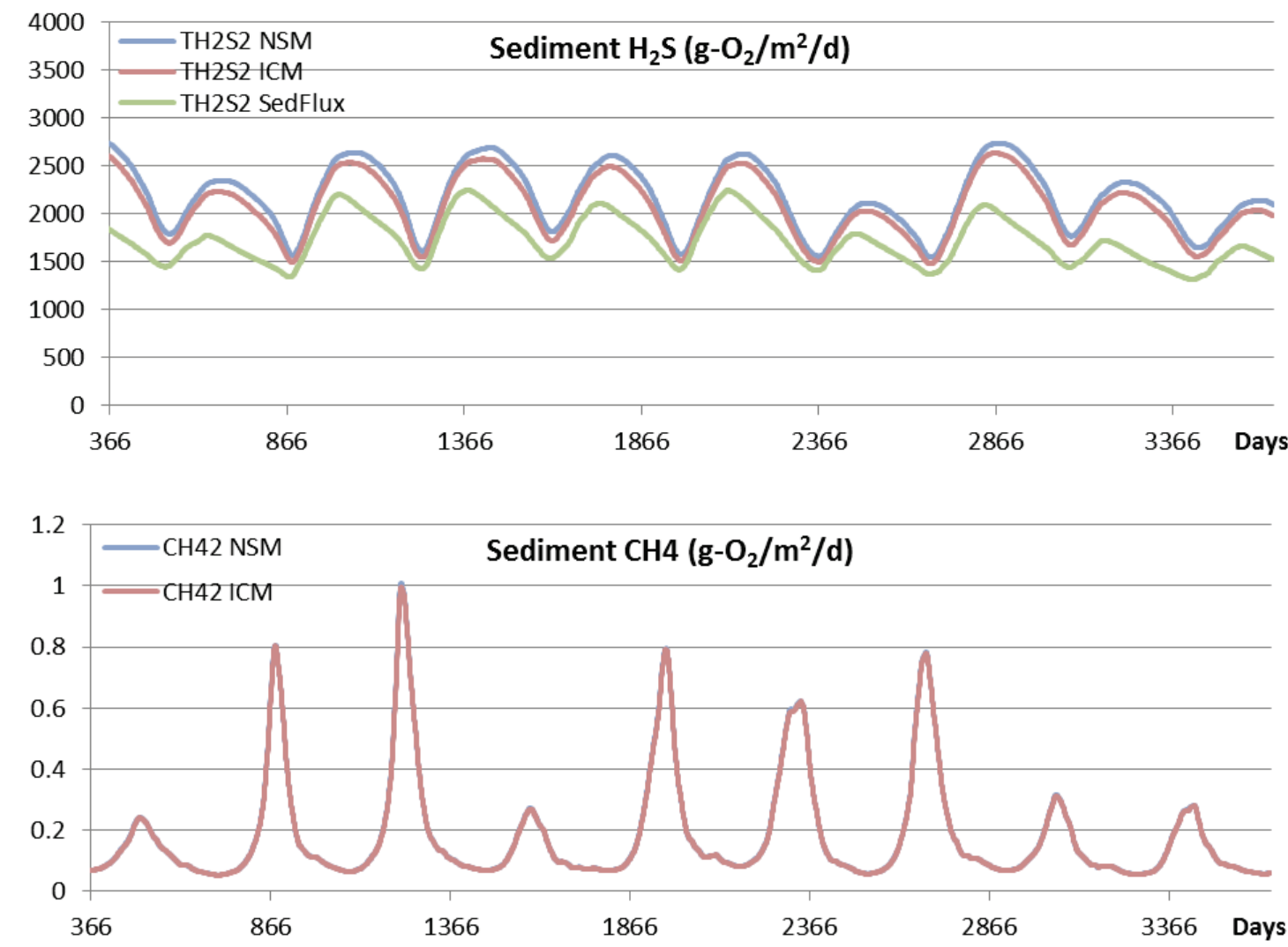

(e)

Sediment concentrations for ammonia ( $\left.\mathrm{NH}_{4}\right)$, nitrate (NO3), total inorganic phosphorous (TIP), sulfide $\left(\mathrm{TH}_{2} \mathrm{~S}\right)$, and methane $\left(\mathrm{CH}_{4}\right)$ in layer 1 follow the same pattern as layer 2. The three models (SedFlux, ICM, and NSMII) produced approximately the same sediment concentrations except sulfide and methane. These differences are attributed to different algorithms implemented by each model.

Figure 8. Comparisons of model predictions of the sediment layer 1's concentrations: (a) NH4, (b) NO3, (c) TIP, (d) $\mathrm{H}_{2} \mathrm{~S}$, and (e) $\mathrm{CH} 4$.

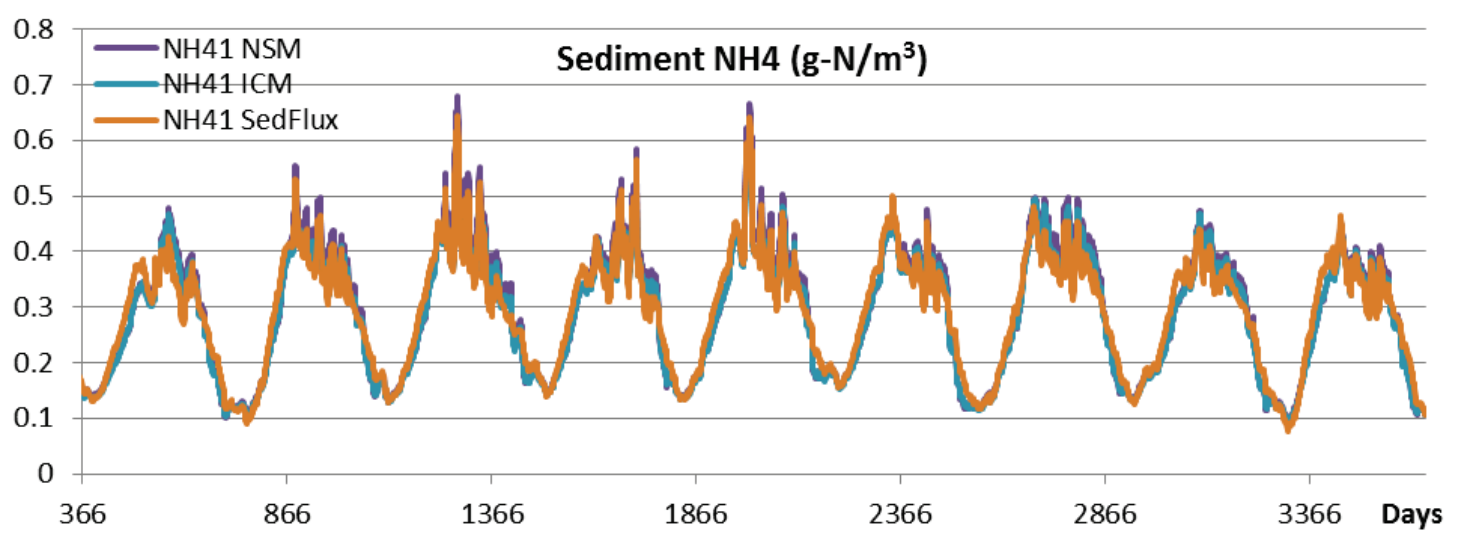

(a) 


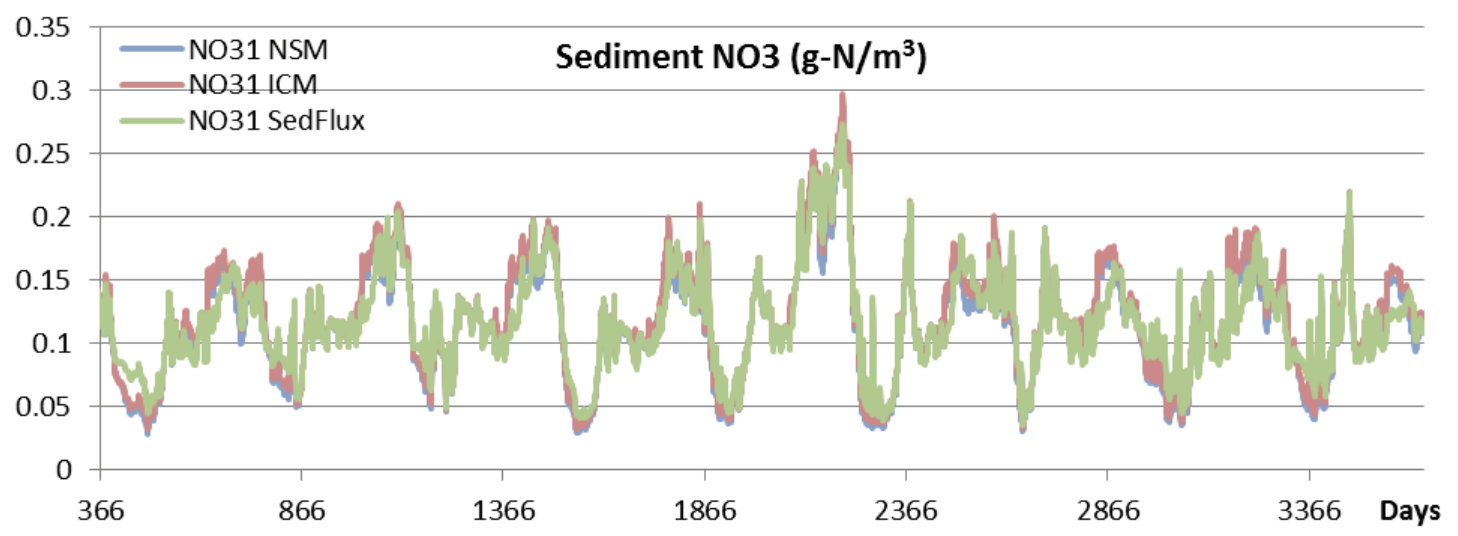

(b)

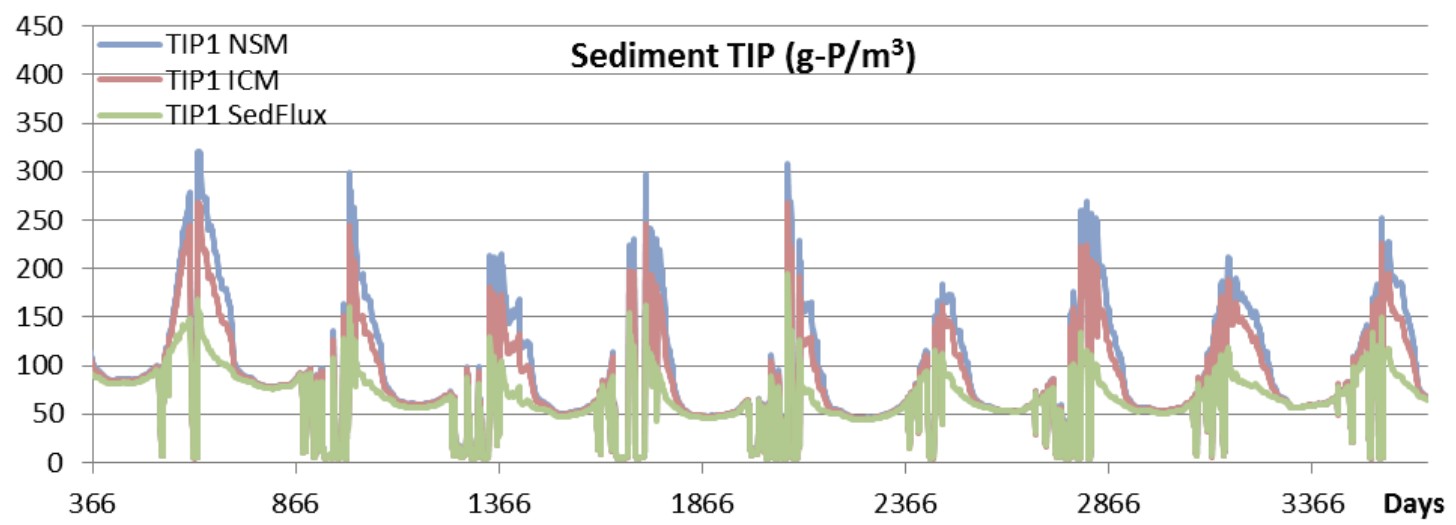

(c)

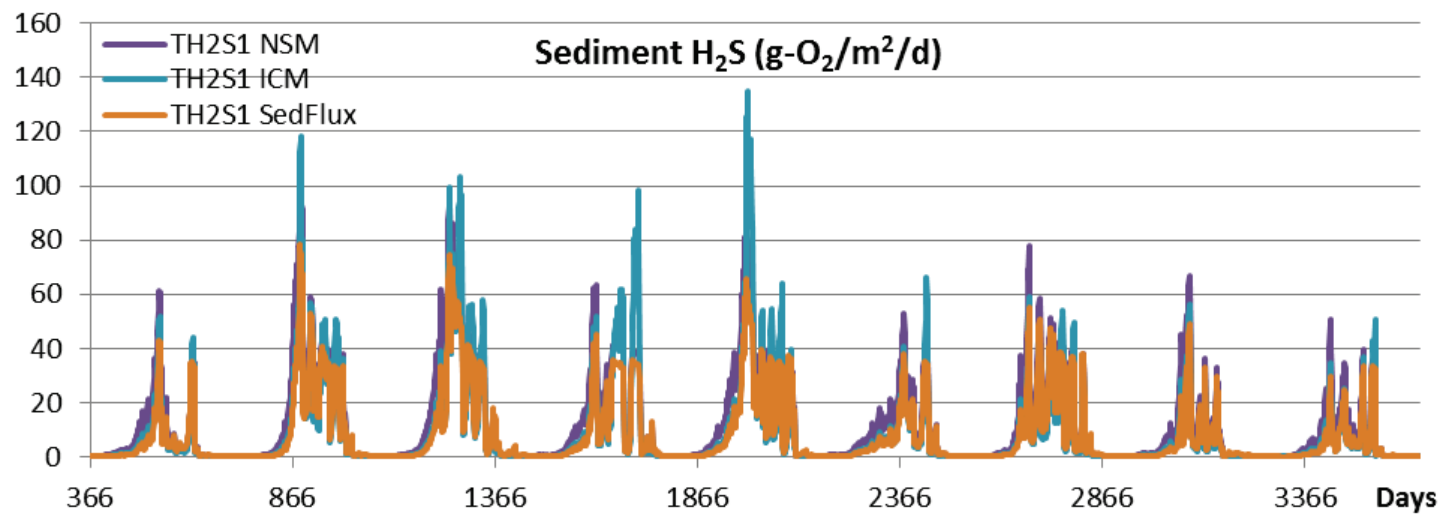

(d)

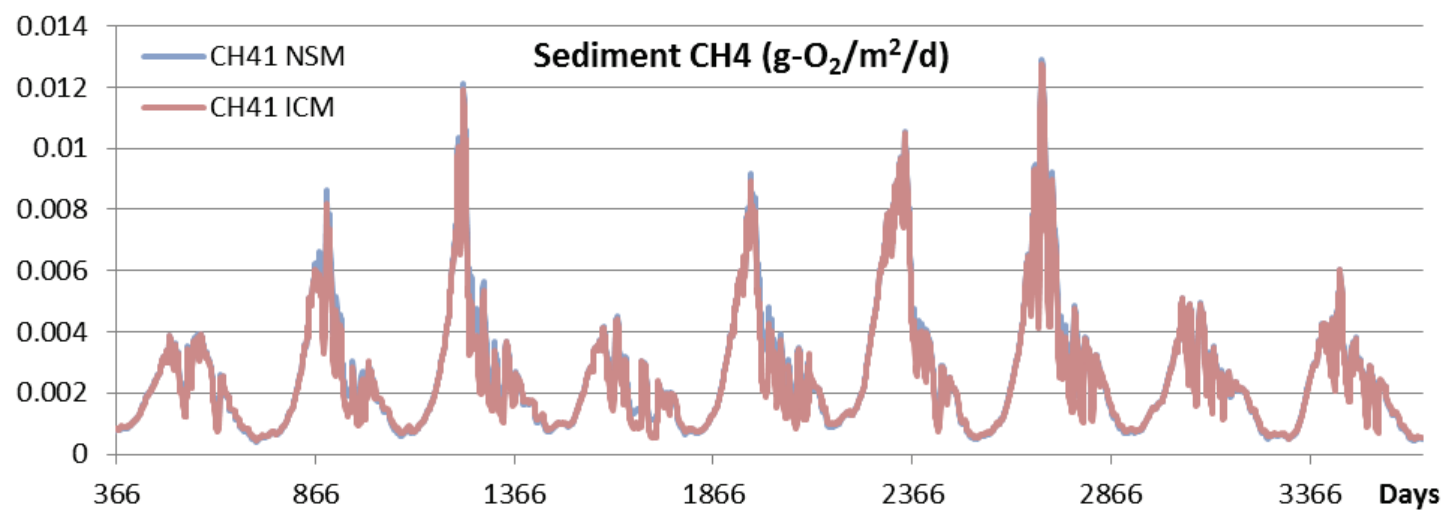

(e) 


\subsubsection{Predictions of sediment oxygen demand and sediment-water fluxes}

SOD is computed by summing all model processes that consume oxygen, including the oxidation of $\mathrm{NH}_{4}, \mathrm{H}_{2} \mathrm{~S}$, and $\mathrm{CH}_{4}$. The CSOD is determined in the ICM and NSMII from both methane and sulfide oxidation. In the SedFlux, either methane or sulfide is used to compute the CSOD. Sediment-water fluxes of dissolved variables ( $\mathrm{NH}_{4}, \mathrm{NO}_{3}$, DIP, $\mathrm{H}_{2} \mathrm{~S}$, and $\mathrm{CH}_{4}$ ) are determined by their concentration differences between the surface sediment layer and the overlying water. The flux may be in either direction across the sediment-water interface, depending on the concentration gradient. Positive fluxes are from benthic sediment to water column. Negative fluxes are from water column to sediments. Model predictions of SOD and sediment-water fluxes for $\mathrm{NH}_{4}, \mathrm{NO}_{3}$, DIP, $\mathrm{CH}_{4}$, and $\mathrm{H}_{2} \mathrm{~S}$ are shown in Figure 9. Seasonal cycles of SOD at this location where the overlying water column may be oxic and hypoxic are out of phase with one another. Strong oxygen limitation of SOD occurs, which is illustrated by occasional, shortlived SOD peaks during summer when DO concentrations are slightly elevated. SOD computed from the SedFlux varied slightly between the SedFlux and ICM and NSMII because only CSOD derived by sediment sulfide is computed in the SedFlux. For the same reason, sediment-water fluxes of methane and sulfide computed from the SedFlux are different from the other two models. Otherwise, the three models (SedFlux, ICM, and NSMII) produced approximately the same results for sediment-water fluxes of ammonia, and dissolved inorganic phosphorus.

Figure 9. Comparisons of SedFlux and NSMII unsteady-state model predictions of the sediment-water fluxes: (a) SOD, (b) NH4, (c) NO3, (d) DIP, (e) $\mathrm{CH} 4$ and (f) $\mathrm{H}_{2} \mathrm{~S}$.

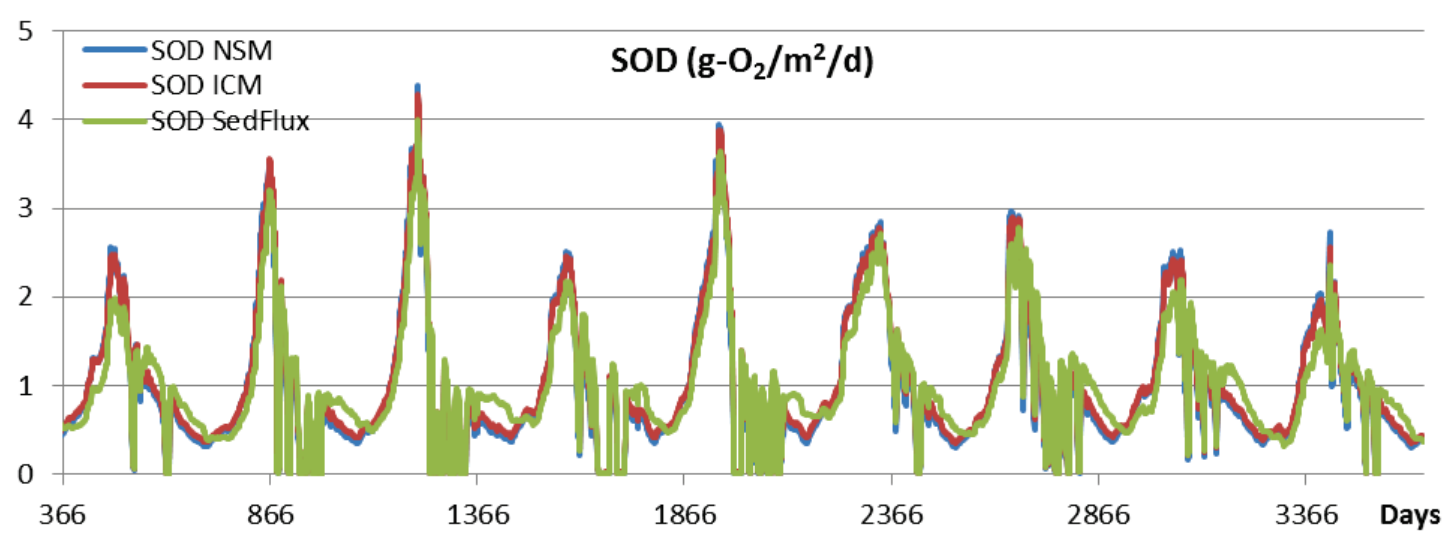




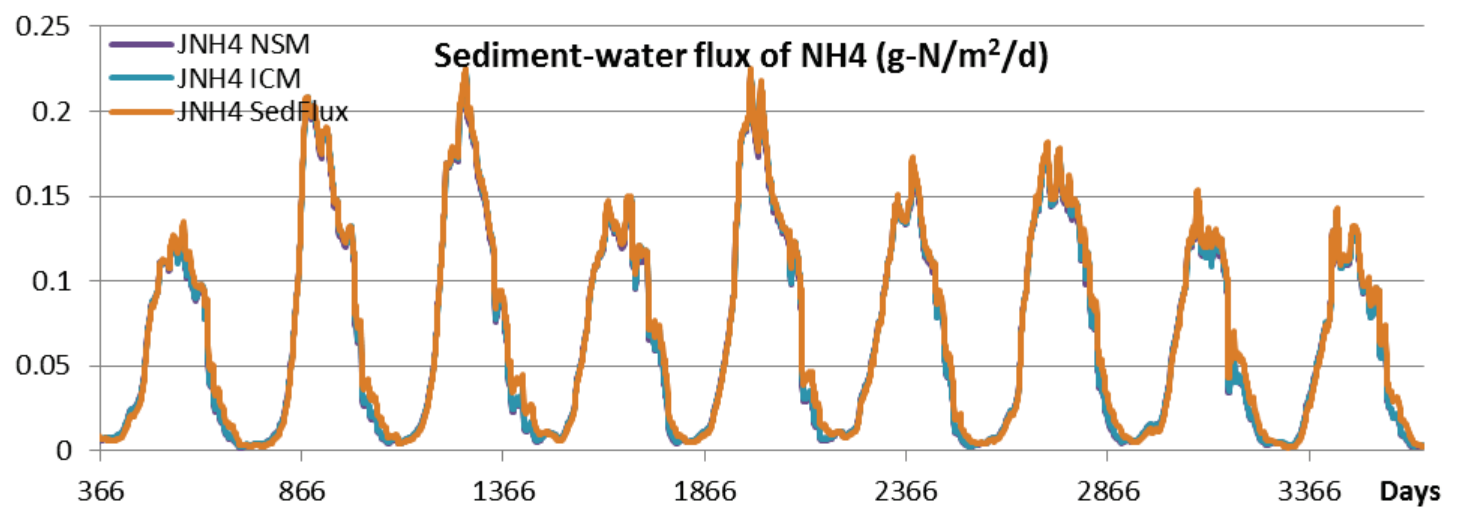

(b)

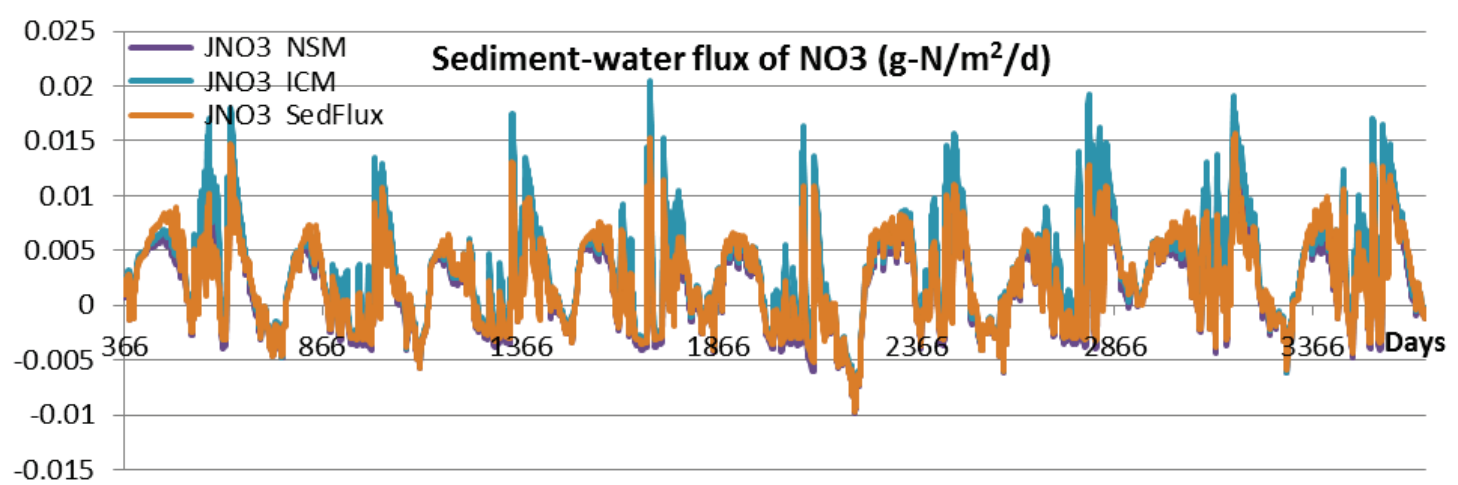

(c)

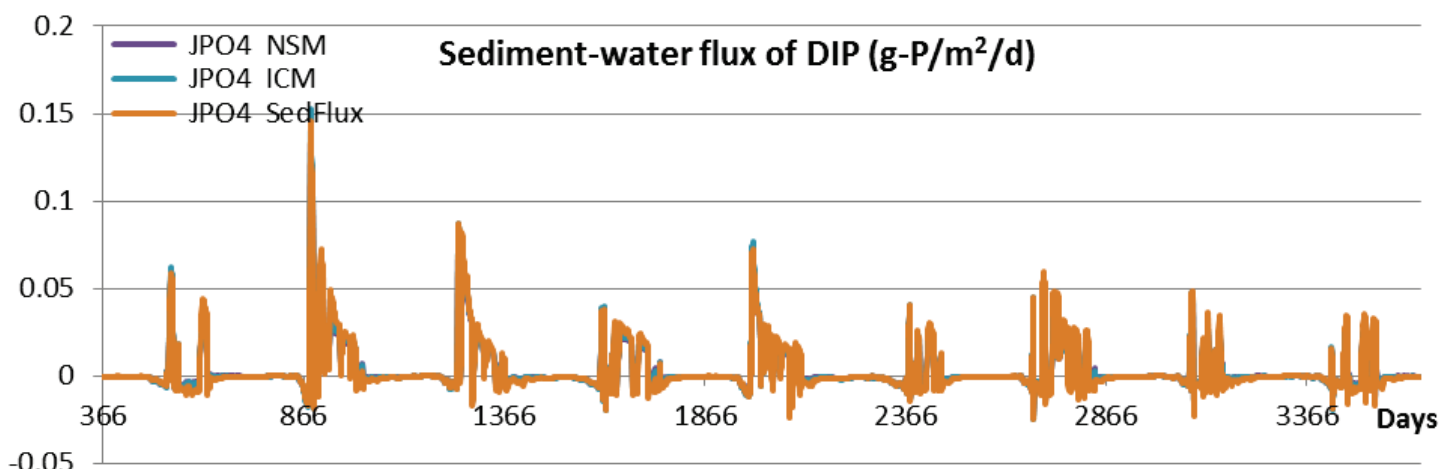

(d)

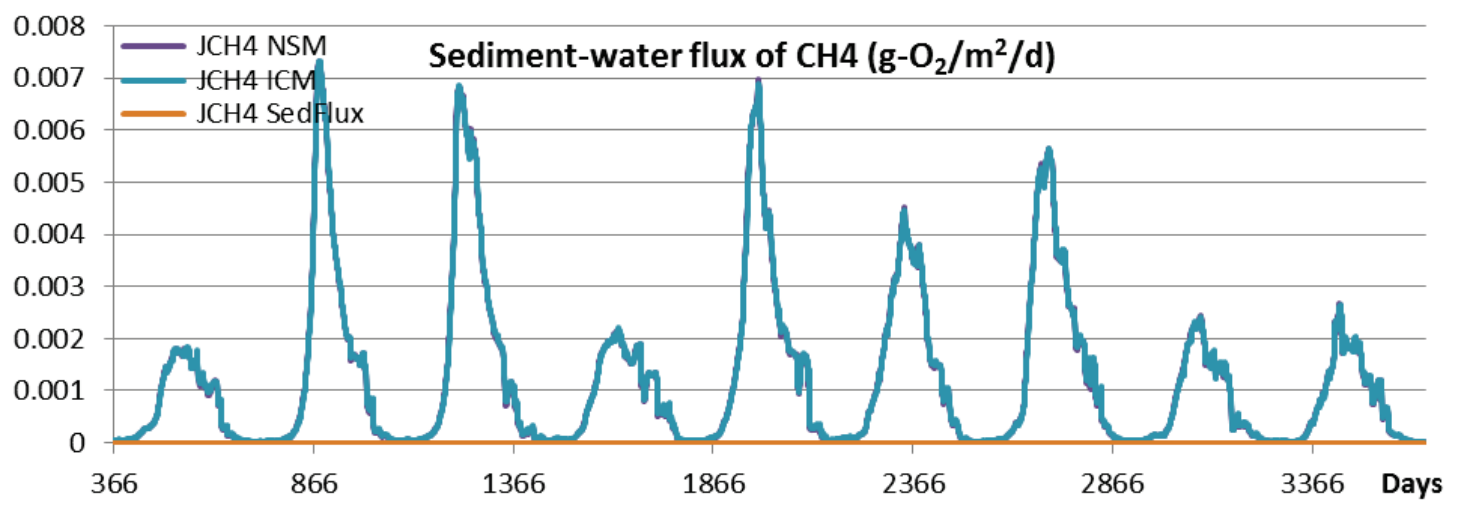

(e) 


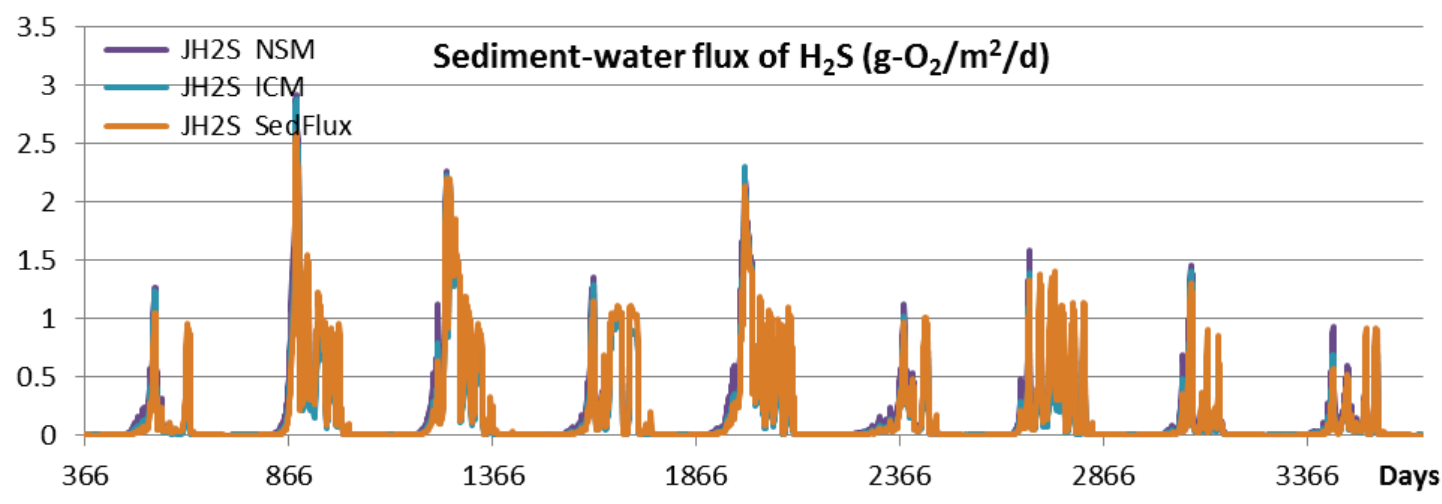

In summary, the NSMII-benthic sediment diagenesis module was able to predict POC, PON, and POP deposition fluxes into each G class in the sediment layer. Inorganic nutrient concentrations in sediment layers 1 and 2 derived by the sediment diagenesis processes were consistently simulated against model results produced by the SedFlux and ICM. The NSMII predictions of SOD and sediment-water fluxes of nutrients matched reasonably well with the model results obtained from the SedFlux and ICM. Some differences among the three models as seen are due to different algorithms implemented in each model. The model validation was successful.

\subsection{Special case testing and sensitivity analysis of NSMII}

This section describes several special testing and validation case studies of the NSMII's sediment diagenesis module.

\subsubsection{NSMII vs. SedFlux steady-state solutions}

Both SedFlux and NSMII include two options for the numerical solutions of mass balance equations of sediment diagenesis state variables: 1) steady-state and 2) unsteady-state. The first option does not require initial conditions for state variables. Initial conditions are required for the second option. This test case provides comparisons of model predictions given by these two models under steady-state conditions. Concentrations of all sediment diagenesis state variables predicted by these two models are identical except methane and sulfide concentrations. The predicted methane and sulfide concentrations varied slightly between the two models. In the SedFlux, sulfide is computed only for the saltwater case, while methane is computed for the freshwater case. Sediment methane is assumed in the SedFlux to be completely mixed for both layers. The methane concentration is then only computed under steady-state solutions. Steady-state model predictions for SOD and sediment-water fluxes of ammonia, ni- 
trate, phosphate, and methane are shown in Figure 10. The two models produced comparable predictions for SOD and nutrient release rates. Temporal variations of SOD between the SedFlux and NSMII are slightly different due to sediment methane concentrations.

Figure 10. Comparisons of SedFlux vs. NSMII steady-state solutions: (a) SOD and sediment-water fluxes: (b) NH4, (c) NO3, (d) $\mathrm{CH} 4$, and (e) DIP.

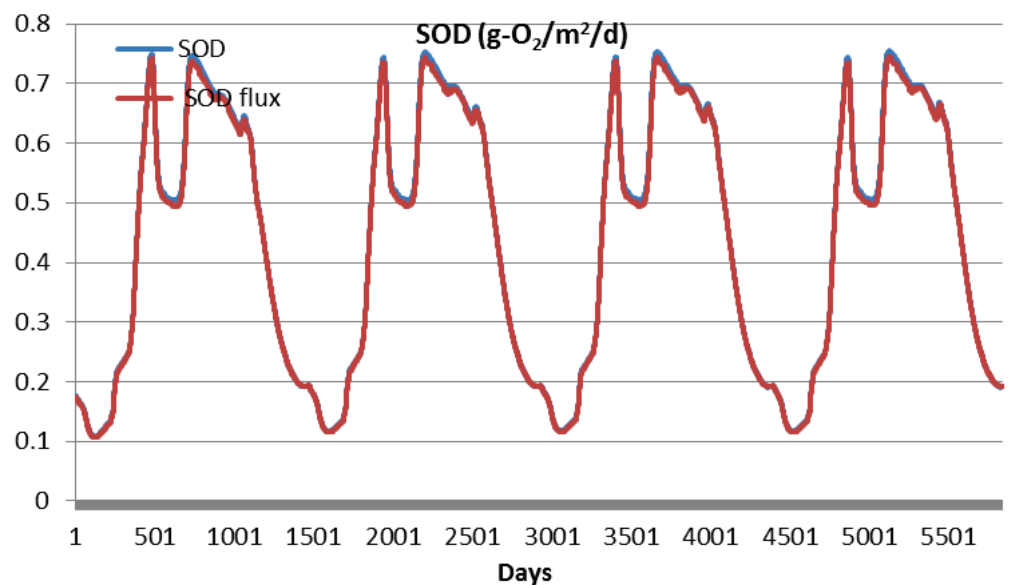

(a)

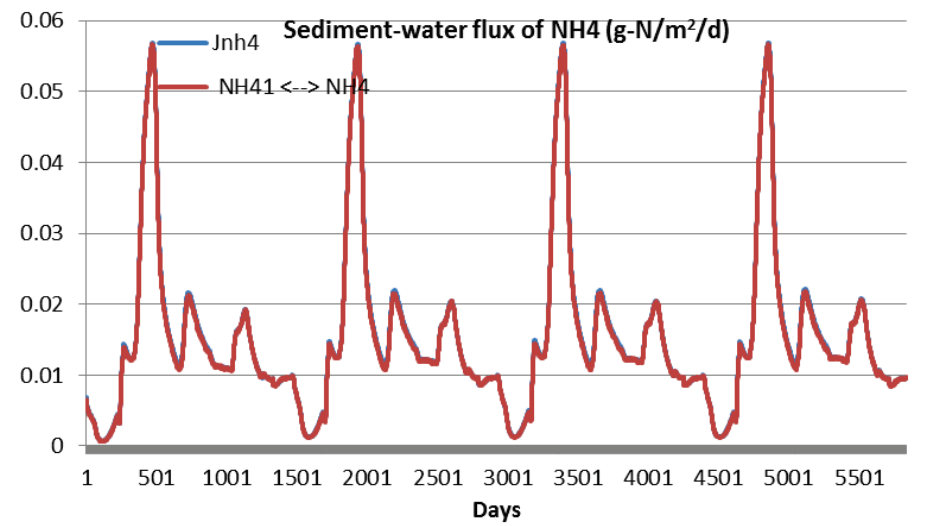

(b)

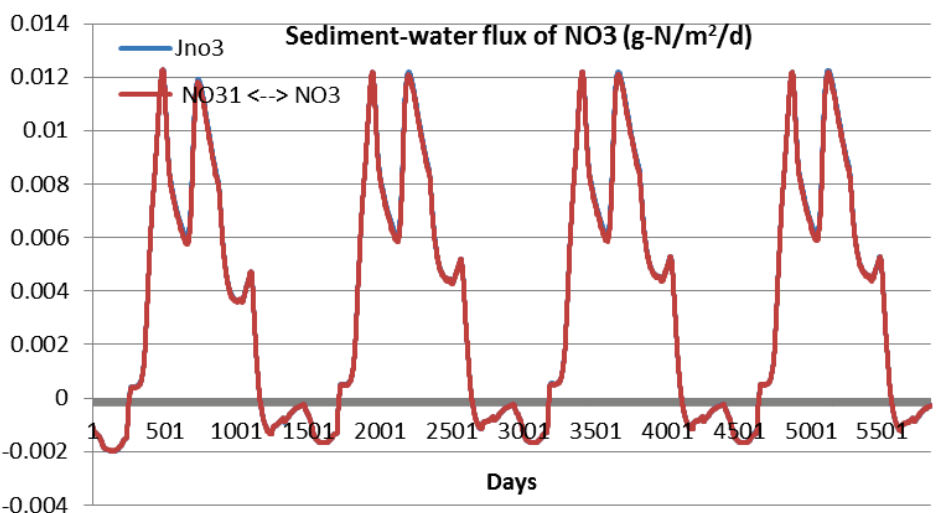

(c) 


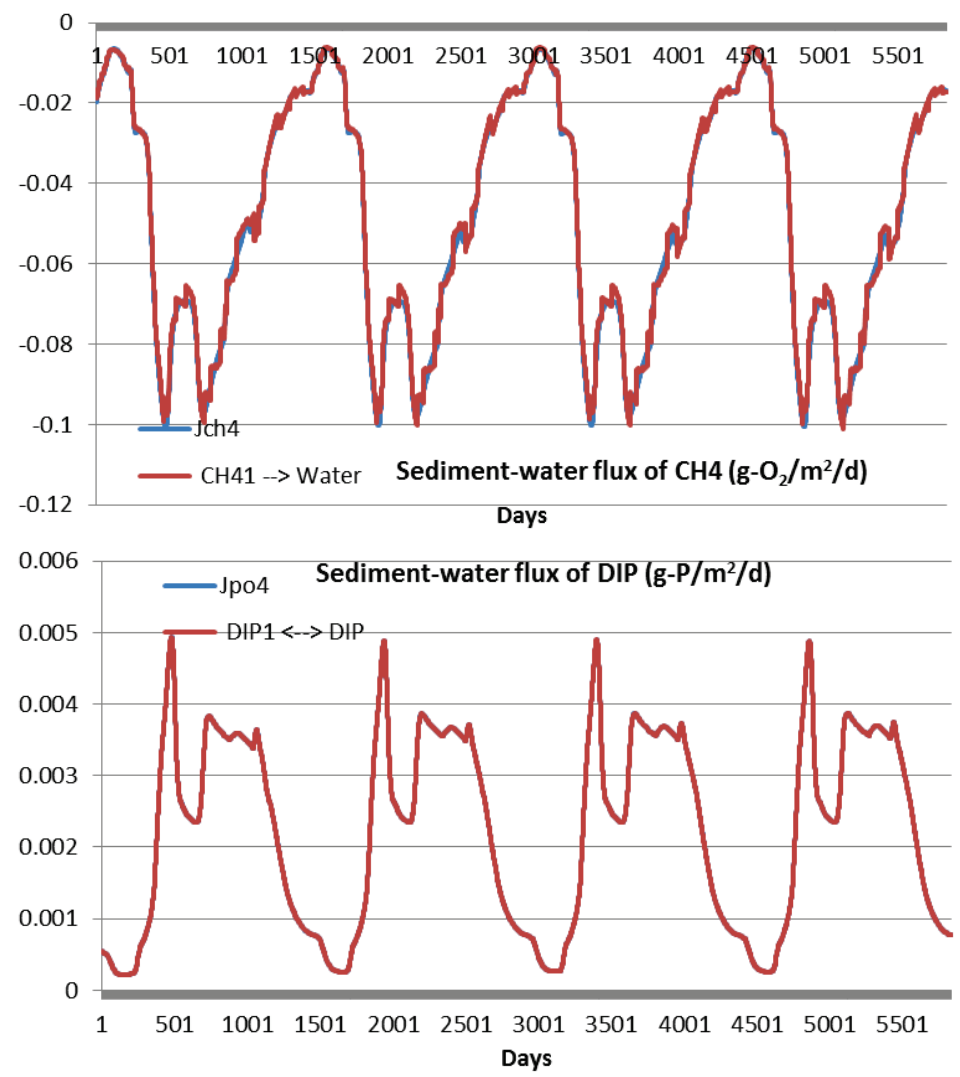

(d)

\subsubsection{NSMII steady-state vs. unsteady-state solutions}

In this validation case, two NSMII model simulations were conducted for the steady-state and unsteady-state conditions. Initial sediment concentrations of all state variables were set to zero for one simulation. Model predictions for sediment layer 2's ammonia $\left(\mathrm{NH}_{4}\right)$, nitrate $\left(\mathrm{NO}_{3}\right)$, dissolved inorganic phosphorous (DIP), sulfide $\left(\mathrm{H}_{2} \mathrm{~S}\right)$, and methane $\left(\mathrm{CH}_{4}\right)$ are shown in Figure 11. The results produced from both steady and unsteady-state solutions are different. Initial sediment concentrations for $\mathrm{NH}_{4}, \mathrm{NO}_{3}$, DIP, $\mathrm{CH}_{4}$, and $\mathrm{H}_{2} \mathrm{~S}$ under unsteady-state solutions have effects on the sediment-water fluxes at the beginning of the simulation period; however, their concentrations reach the same after that. Therefore, initial sediment concentrations of each state variable from unsteady-state solutions have minimum impact on the long-term concentration of each state variable predicted by the NSMII.

The steady-state mode of the sediment diagenesis module is typically used to estimate initial conditions. A steady-state computation allows the model to compute the initial conditions based upon the initial water column concentrations and organic matter settling fluxes, assuming steady-state con- 
ditions. As advised by Di Toro (2001), a common approach to refine the initial conditions is through the use of a quasi-dynamic approach. In this approach, the model is run for a period of a year or more, with reasonably repeating water column conditions, and the predicted concentrations in diagenesis segments at the end of that period are used to refine and replace the specified initial conditions. This process is repeated until the resulting predictions approach a quasi-steady state.

Figure 11. Comparisons of NSMII steady- vs. unsteady-state solutions of sediment layer 2's concentrations: (a) NH4, (b) NO3, (3) DIP, (4) $\mathrm{H}_{2} \mathrm{~S}$, and (c) $\mathrm{CH} 4$.

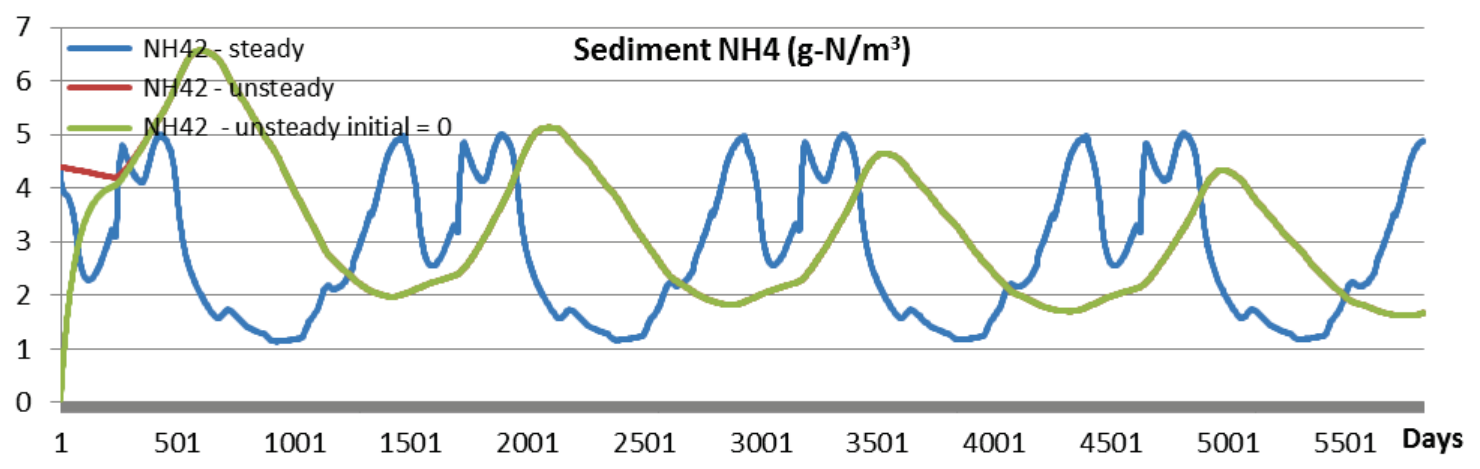

(a)

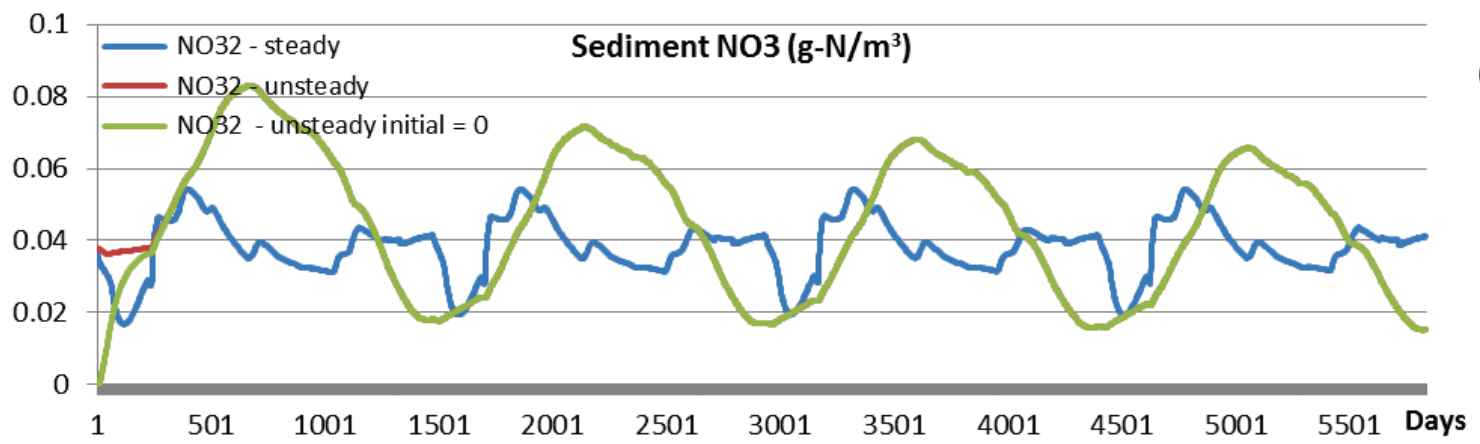

(b)

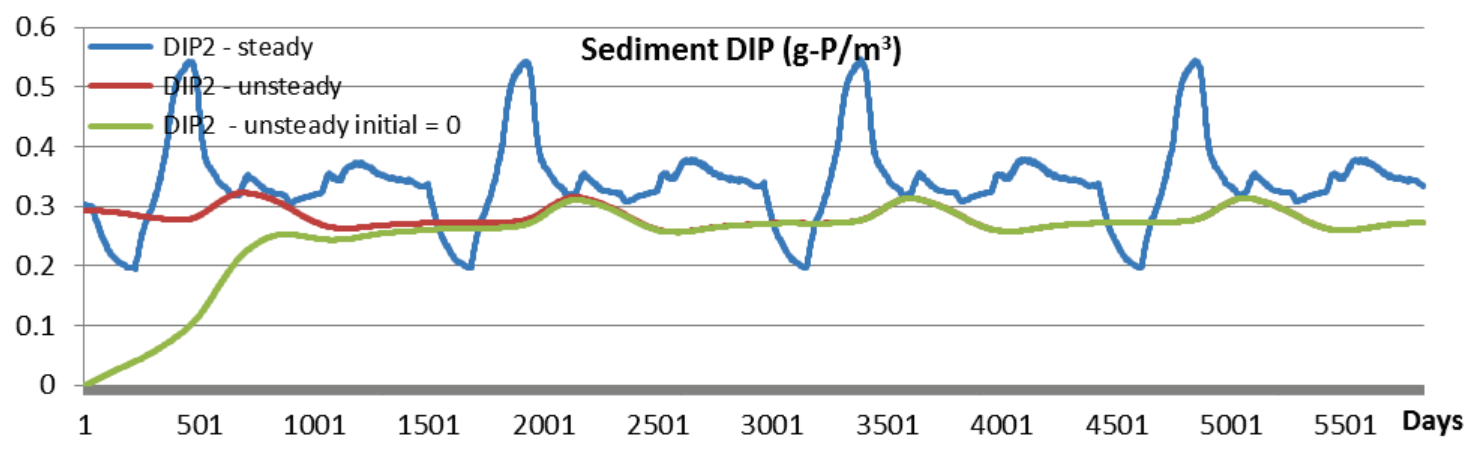



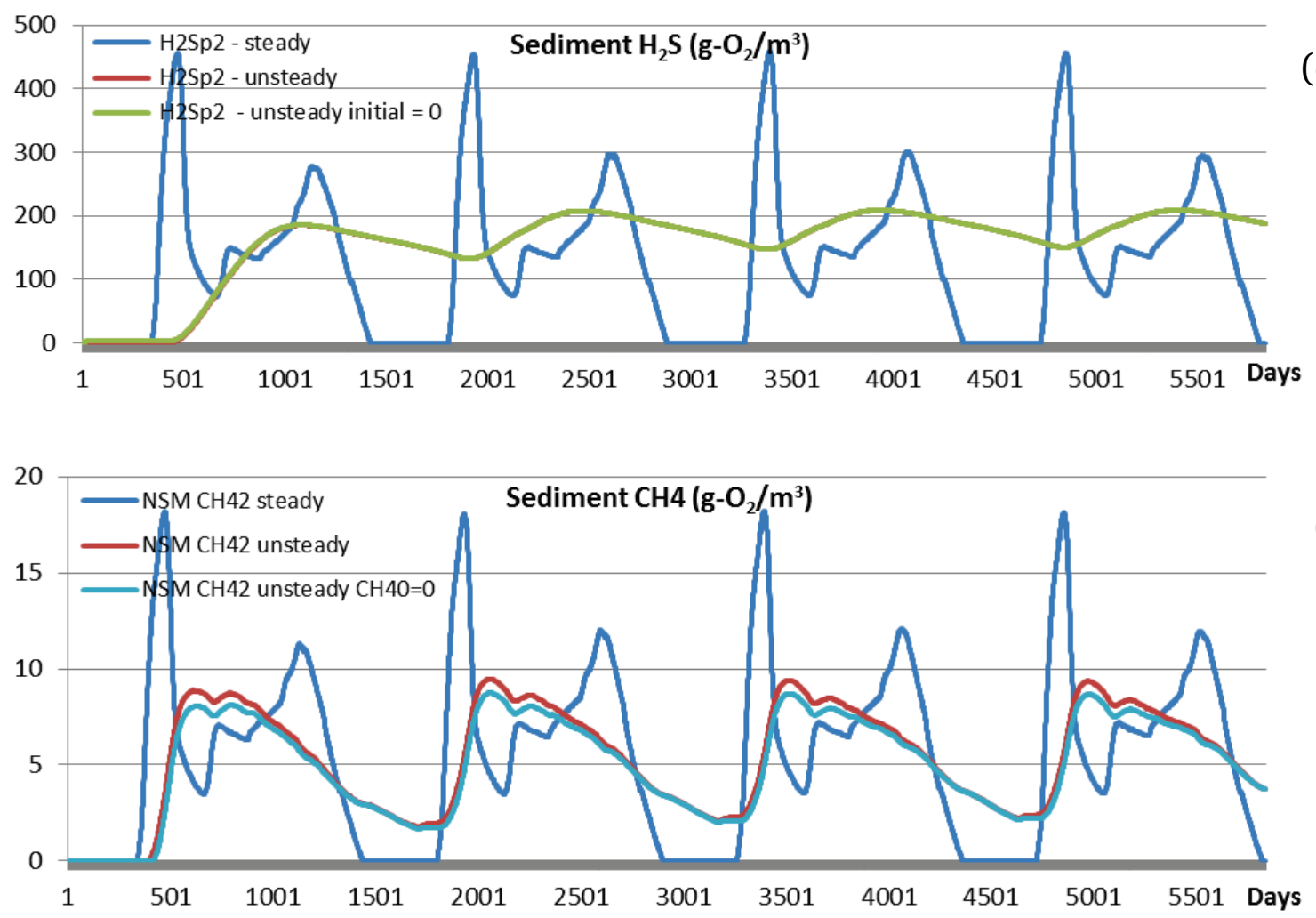

(e)

\subsubsection{NSMII analytical vs. numerical solutions of sediment methane}

The dissolved methane produced by carbon diagenesis can be oxidized in the aerobic layer, released as a flux to the overlying water column, or become gaseous when its concentration exceeds saturation. The methane saturation is used to establish an upper limit for the sediment methane concentration in layer 2 and corresponds to the CSOD that results from the methane oxidation. If the methane resulting from the sediment carbon diagenesis is greater than the methane produced at saturation, the CSOD is computed from the saturation value and the remaining methane may be stored and removed as gas bubbles (Rudd and Taylor 1980). The loss of methane as bubbles is an important sink. For this validation test, the POC depositional flux from the water column was increased by a factor of 100 over that used in the above test case. This test was included to allow sufficient POC flux to the sediment bed so that the resulting methane production would exceed the saturated concentration. In this test case, modeled sediment methane concentration in layer $2\left(\mathrm{CH}_{4}\right)$ under the numerical solution is set to saturation ( $\left.\mathrm{CH}_{4} \mathrm{~s}\right)$ as shown in Figure 12(a). In the NSMII, it is assumed that super-saturation does not occur and that all methane produced in excess of the saturation concentration is immediately trans- 
ferred to gas bubbles. This means that all methane produced after the establishment of the saturation concentration is lost to the atmosphere.

An analytical solution is used to determine the steady-state flux of dissolved methane corrected for gas loss delivered to the aerobic sediments and the oxygen consumed by oxidation of methane. In this approach, sediment methane is only computed in layer 1 . Comparisons of the gas losses of sediment methane as bubbles, CSOD, and sediment-water flux of methane under analytical and numerical solutions are shown in Figure 12(b), 12 (c), and 12(d), respectively. CSOD computed from the numerical solution is lower than the analytical solution, having a 2 to $3 \mathrm{~g}-\mathrm{O}_{2} / \mathrm{m}^{3}$ difference at the CSOD peak. The sediment-water flux of methane is also lower than the analytical solution. The gas losses of sediment methane computed from the numerical solution is higher than the analytical solution. If the methane saturation is exceeded, the numerical solution is not appropriate since the CSOD becomes constant and hits a ceiling (Chapra 1997).

Figure 12. Comparisons of NSMII analytical vs. numerical solutions of sediment methane: (a) layer 2's CH4, (b) CSOD, (c) CH4 loss, and (d) sediment-water flux of CH4.
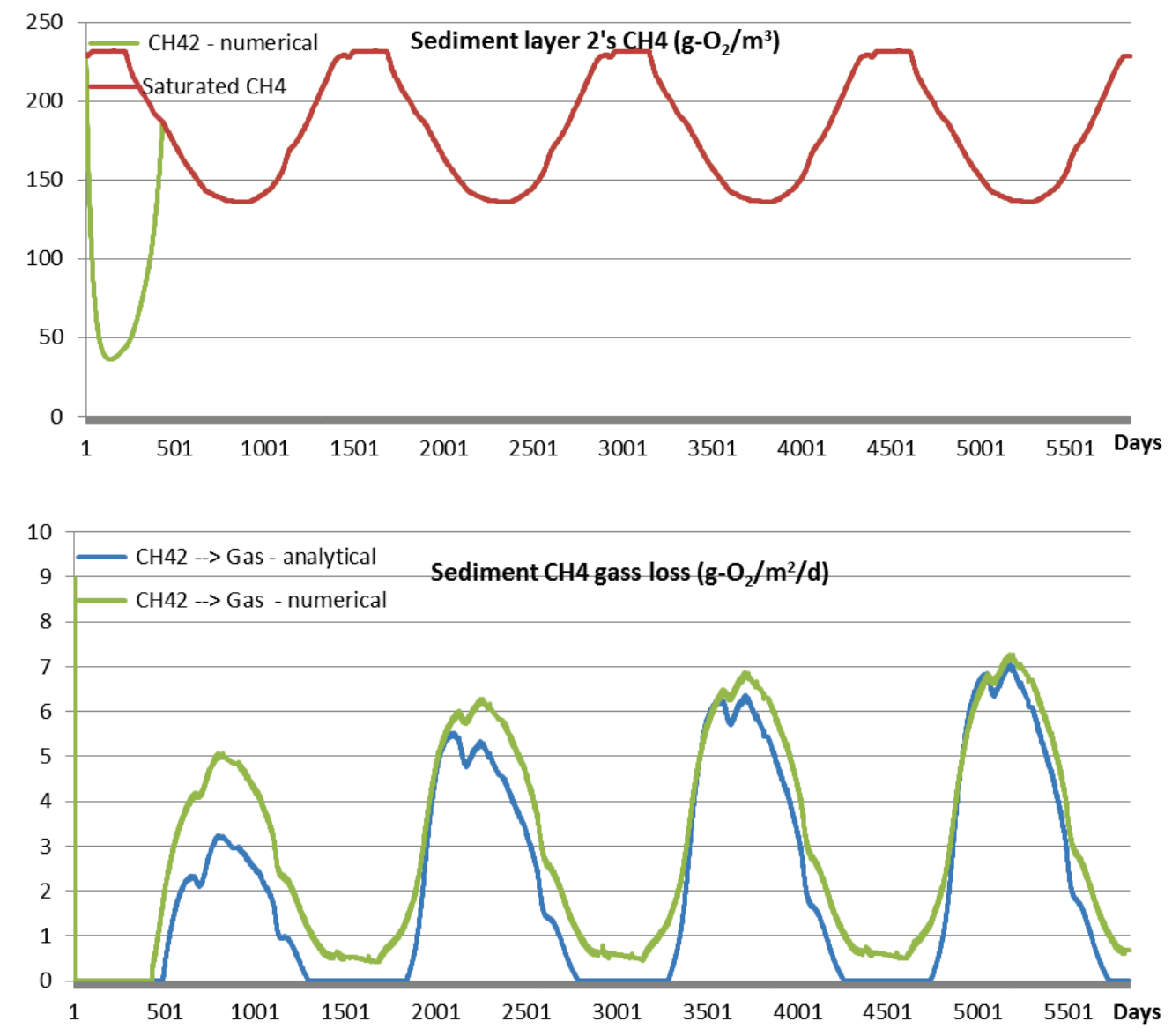


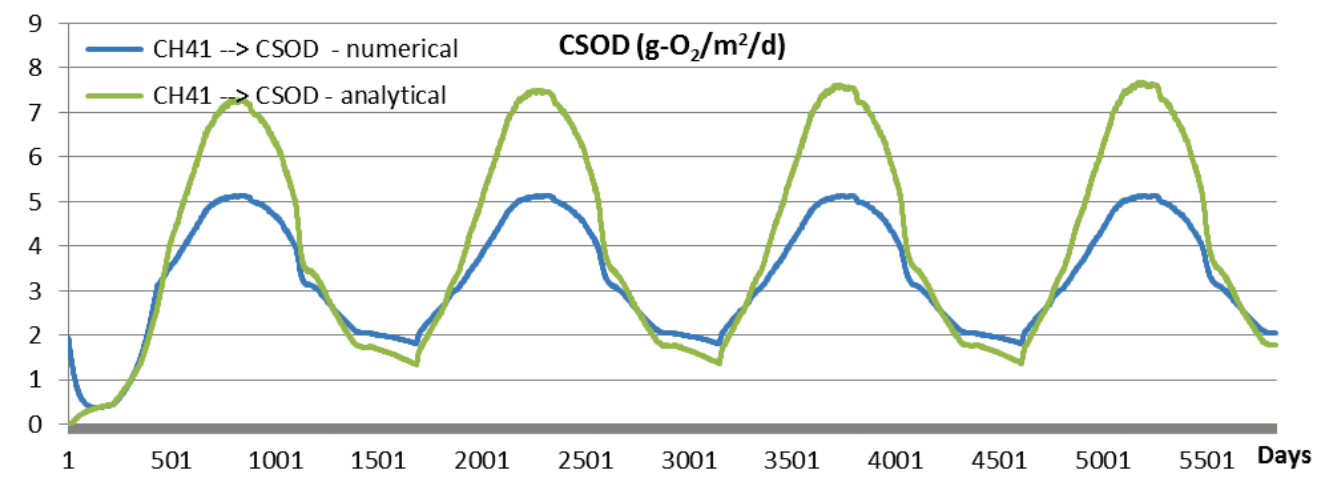

(c)

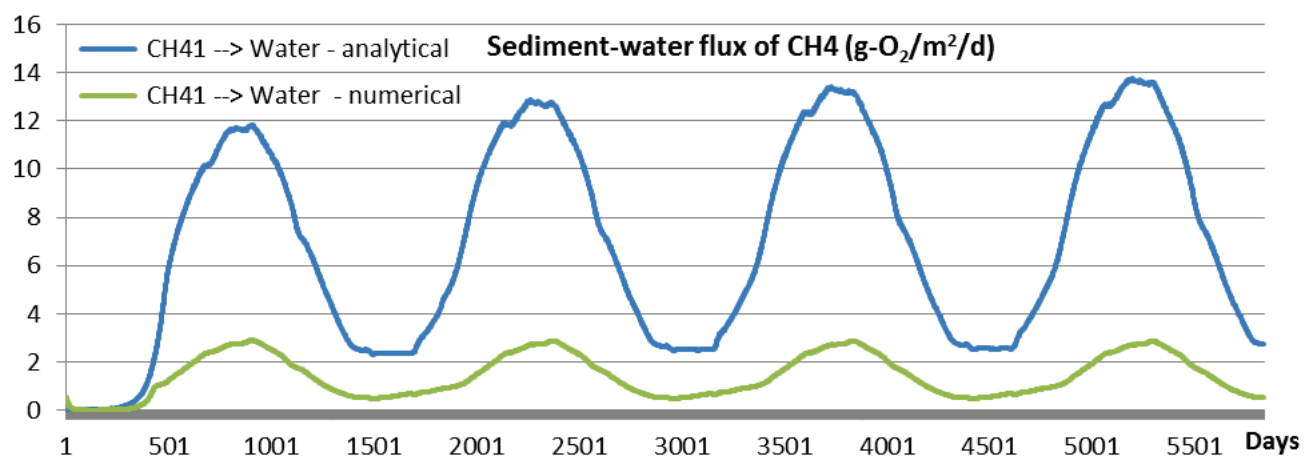

\subsubsection{Comparisons of the diagenesis rates of three sediment organic matter classes (G1, G2, G3)}

Sediment diagenesis (mineralization) reactions occur in the second layer. The heterogeneous nature of sediment organic matter is recognized and simulated by adopting a multi-G approach described by Di Toro (2001). Three "G classes" (labile, refractory, inert) are modeled in the NSMII. Labile, refractory, and inert distinctions are based upon the time-scales of oxidation or decomposition. The G1 fraction has a half-life of 20 days. The G2 fraction has a half-life of one year. The G3 fraction undergoes no significant decay before burial into deep, inactive sediments. In this validation case, digenesis process of the three G classes of sediment POC, PON and POP is tested and compared with a steady-state solution. The steady- and unsteady-state model predictions for sediment POC, PON and POP G1 and G2 classes are shown in Figure 13. The POC, PON and POP G class 1 approached the steady-state concentrations relatively quickly, while the predictions for $\mathrm{G}$ class 2 did not reach a steady state by the end of the 1000day simulation. This test case indicates that it is necessary to divide the sediment organic matter into multiple groups. 
Figure 13. Comparisons of NSMII predictions of the sediment concentrations under the steady- and unsteady-state solutions: (a) POC G1, (b) POC G2, (c) PON G1, (d) PON G2, (e) POP G1, and (f) POP G2.
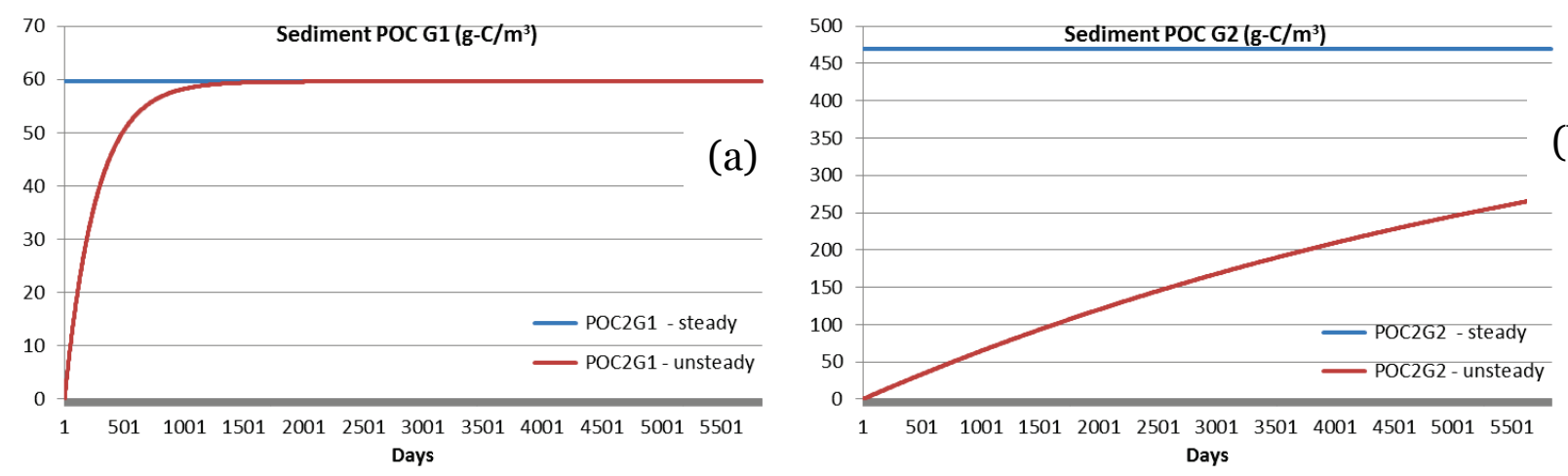

(b)
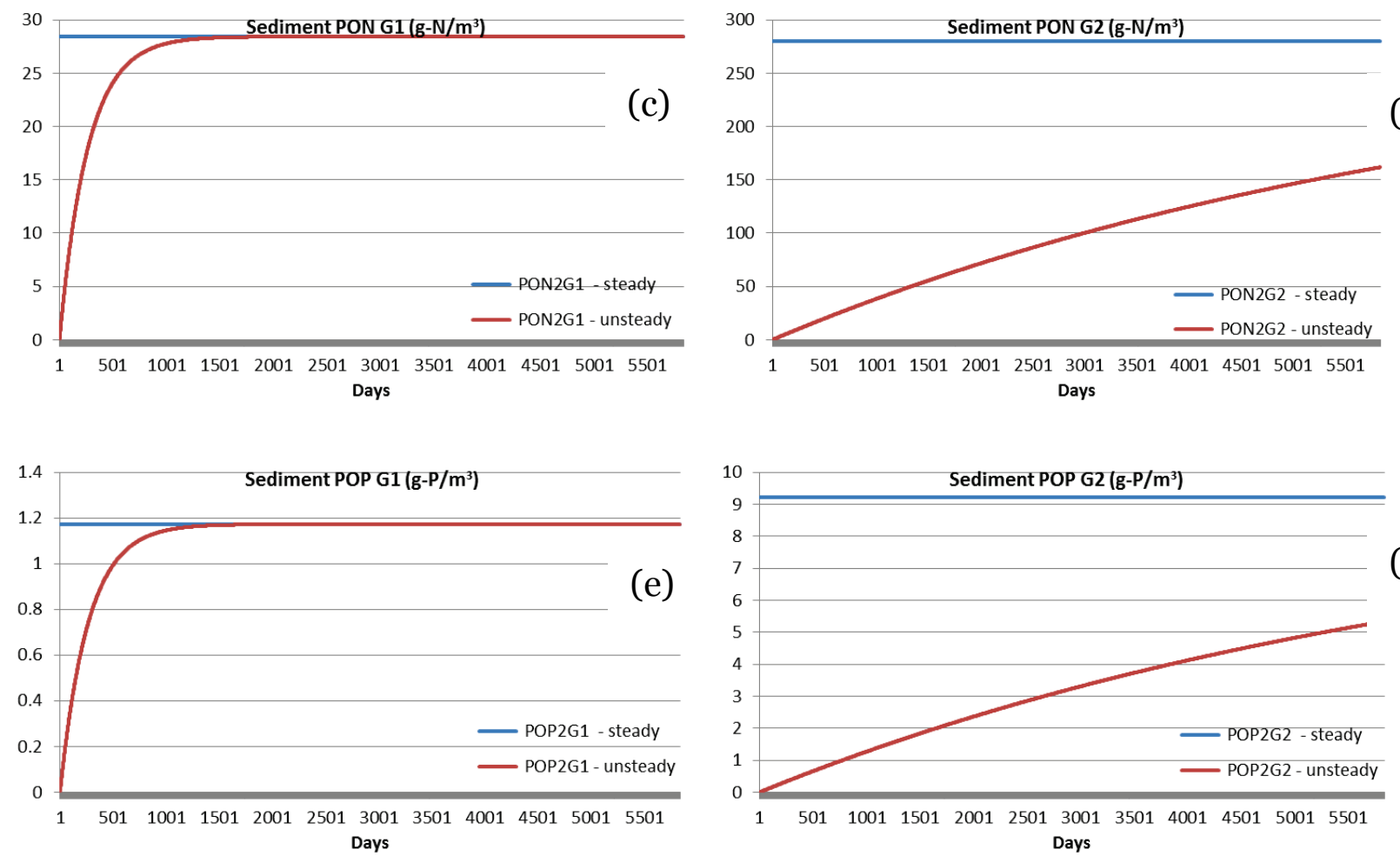

\subsubsection{Sensitivities of the water column depositional rates}

Sensitivity analysis is an important part of the model testing and validation. In this validation case, sensitivity analysis of depositional rates of organic matter from the water column was used for determining the most important forcing functions as well as the potential influence of SOD and release of phosphate, ammonia, and nitrogen from the sediment. The input of organic matter to the sediment-water interface is one of the most important chemical inputs driving the sediment diagenesis. In this sensitivity analysis, water column concentrations of POC, PON, and POP speci- 
fied in the above tests were reduced by $20 \%, 50 \%$, and $90 \%$, respectively. Model predictions for SOD and sediment release of $\mathrm{NH}_{4}, \mathrm{NO}_{3}, \mathrm{H}_{2} \mathrm{~S}, \mathrm{CH}_{4}$, and DIP are shown in Figure 14. The results show that reduced depositional loads produced lower SOD and sediment-water fluxes of $\mathrm{NH}_{4}, \mathrm{NO}_{3}$, $\mathrm{H}_{2} \mathrm{~S}, \mathrm{CH}_{4}$, and DIP. The sediment concentrations of both organic and inorganic substances were reduced proportionally to depositional fluxes from the water column. Therefore, depositional fluxes of organic matter have important influence on the benthic sediment concentrations and nutrient releases. The SOD and sediment release of nutrients are most sensitive to different depositional rates without considering dynamic sedimentation processes.

Figure 14. Sensitivities of water column organic matter deposition rates on sedimentwater fluxes: (a) SOD, (b) NH4, (c) NO3, (d) $\mathrm{H}_{2} \mathrm{~S}$, and (e) DIP.

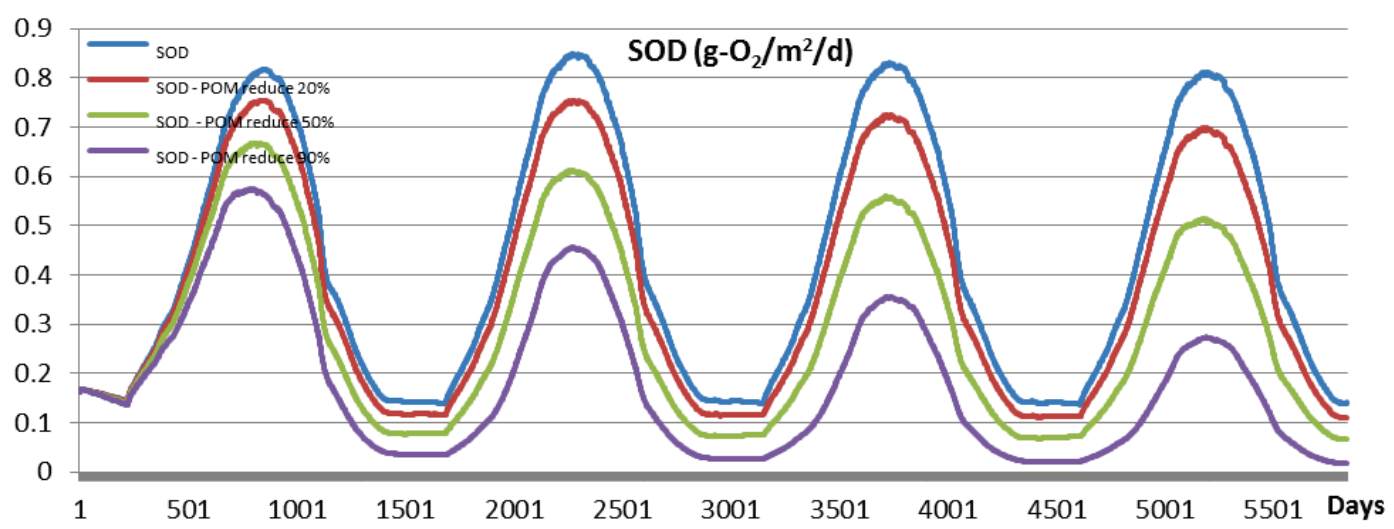

(a)

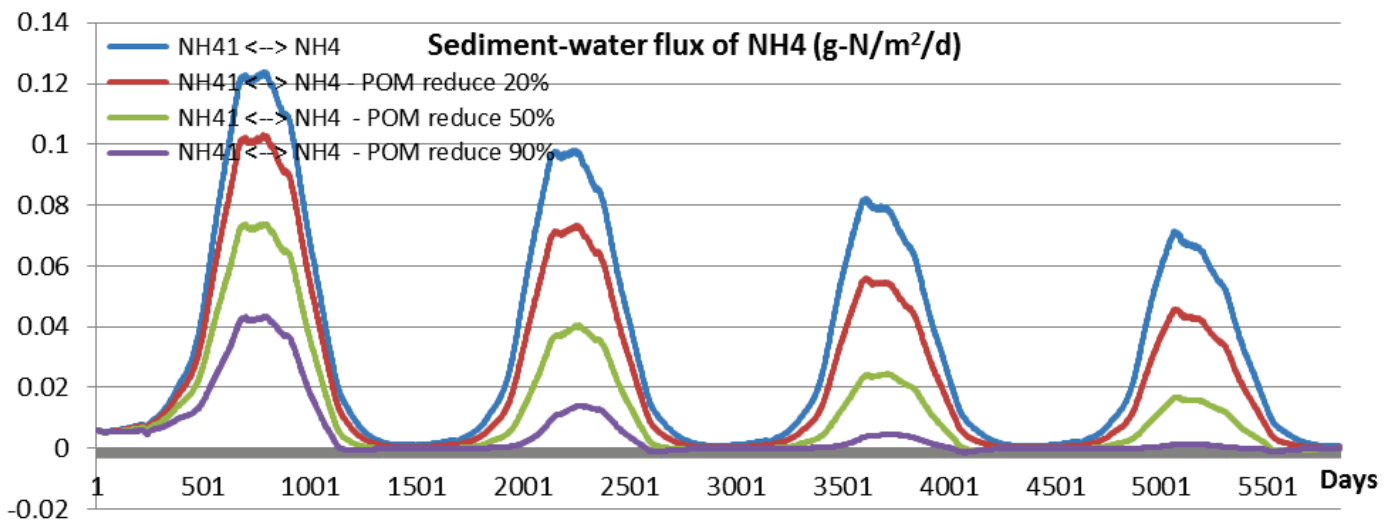



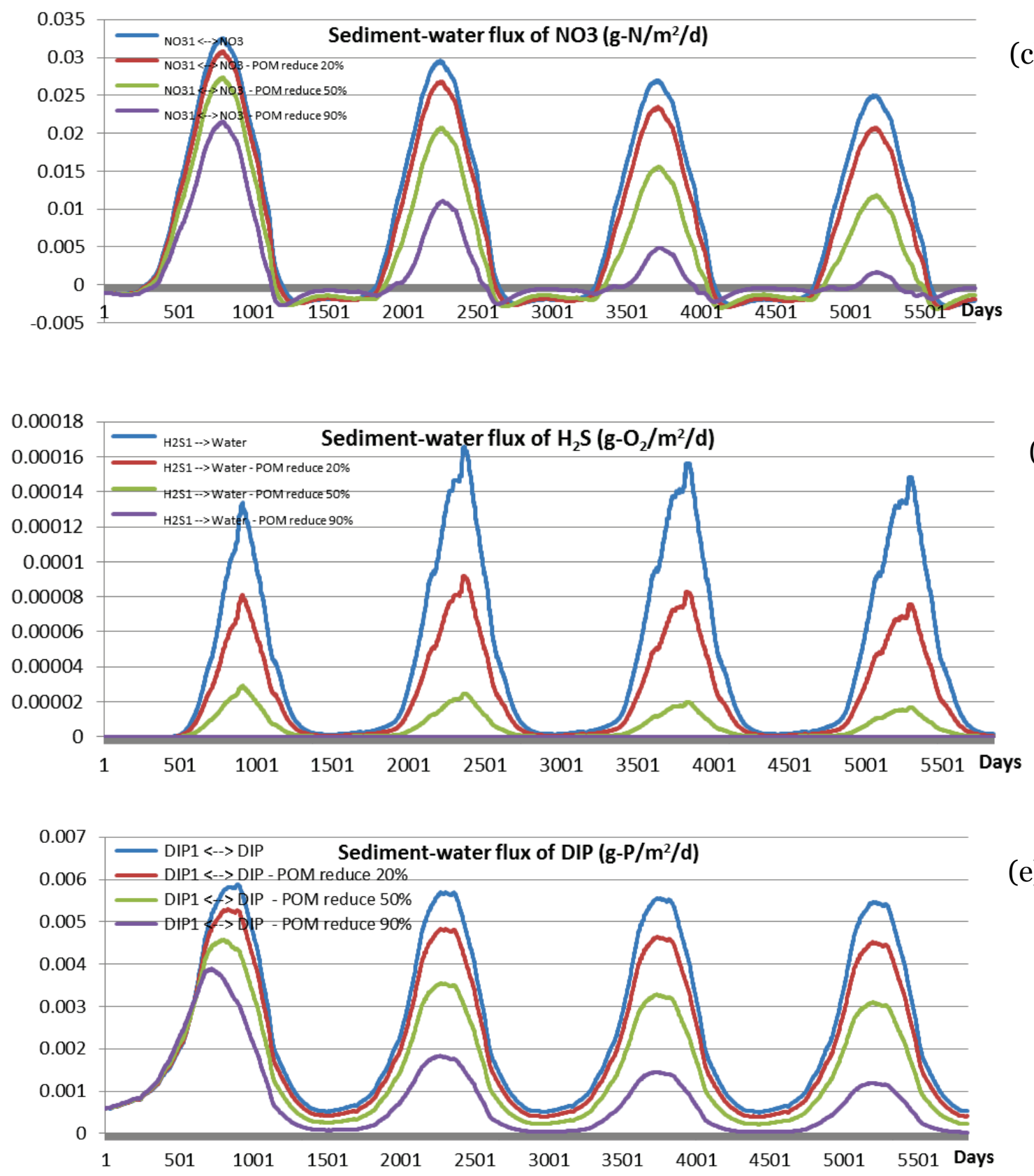

\subsubsection{Sensitivities of the deep burial velocities}

In the sediment diagenesis module, the active sediment layer does not move vertically, its position relative to the sediment-water interface changes as additional material is deposited on the bottom. Thus, deposition of particulate matter at the sediment water interface results in older sediments moving further from that boundary. The resuspension process results in older sediments moving from the sediment-water interface and is not included in the model. Only burial mechanism establishes the verti- 
cal position of constituents in the sediment profile. In applying the NSMII, the burial velocities specified in terms of input parameters are not associated with the flux of total suspended solids (inorganic and organic) from the overlying water. In this sensitivity analysis, the burial velocity was increased by a factor of 10 and 100 than that used in the above test case $\left(\mathrm{w}_{2}\right.$ $=4.928 \cdot 10^{-5} \mathrm{~m} / \mathrm{d}$ ). No burial was also included to test the sensitivity of burial velocities on the SOD and sediment release of nutrients. Model predictions for SOD and sediment release of $\mathrm{NH}_{4}, \mathrm{NO}_{3}$, and DIP are shown in Figure 15. The results show that increased deep burial velocities produced lower SOD and sediment-water fluxes of $\mathrm{NH}_{4}, \mathrm{NO}_{3}$, and DIP. The sediment release of nitrogen and phosphorous was reduced at the sites where the deep burial rate was increased. However, the magnitude of the burial velocity influenced by the depositional flux of solids from the water column and the compaction are not included in the current model.

Figure 15. Sensitivities of deep burial velocities on the sediment-water fluxes: (a) SOD, (b) NH4, (c) NO3, and (d) DIP.
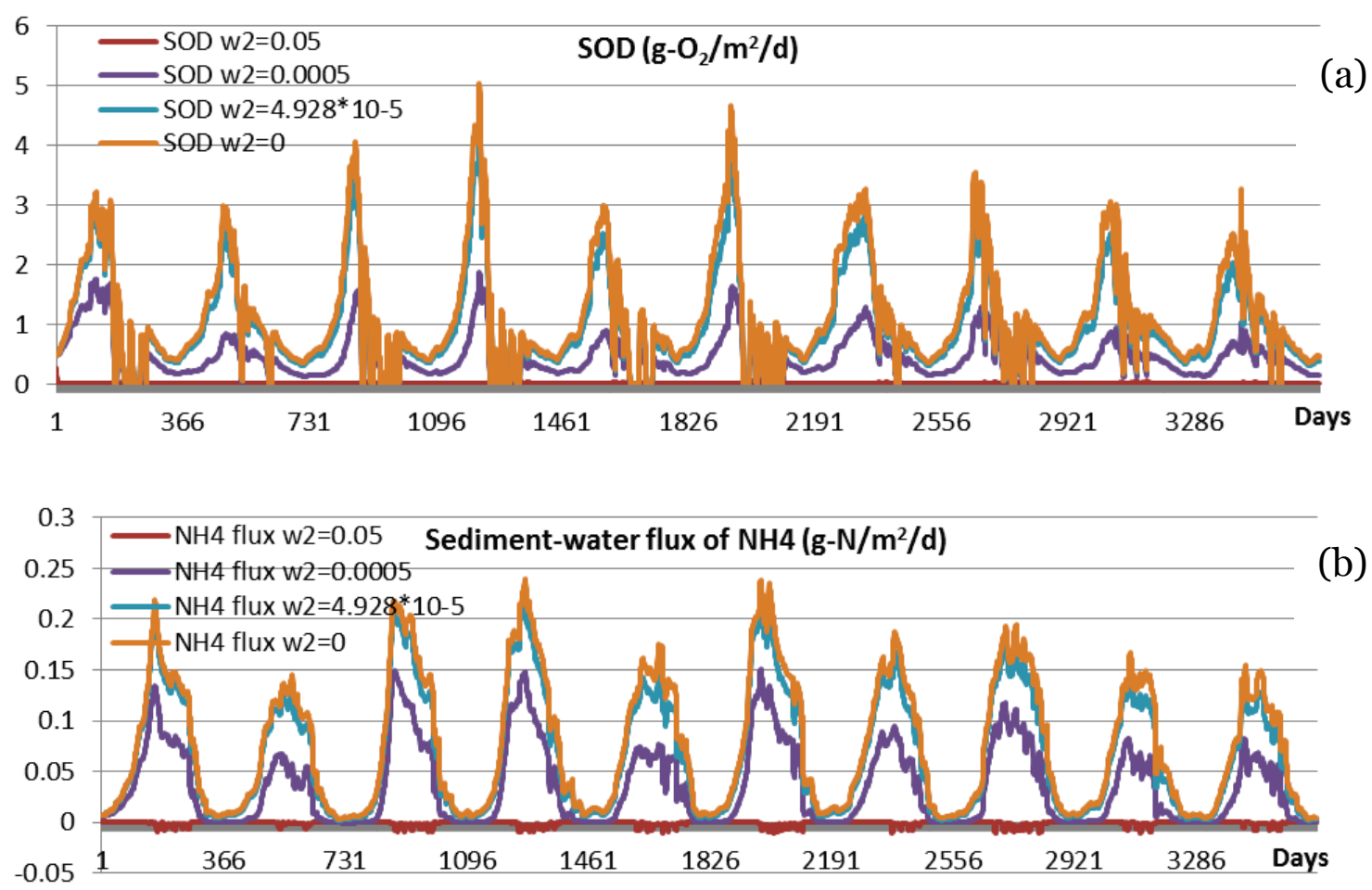

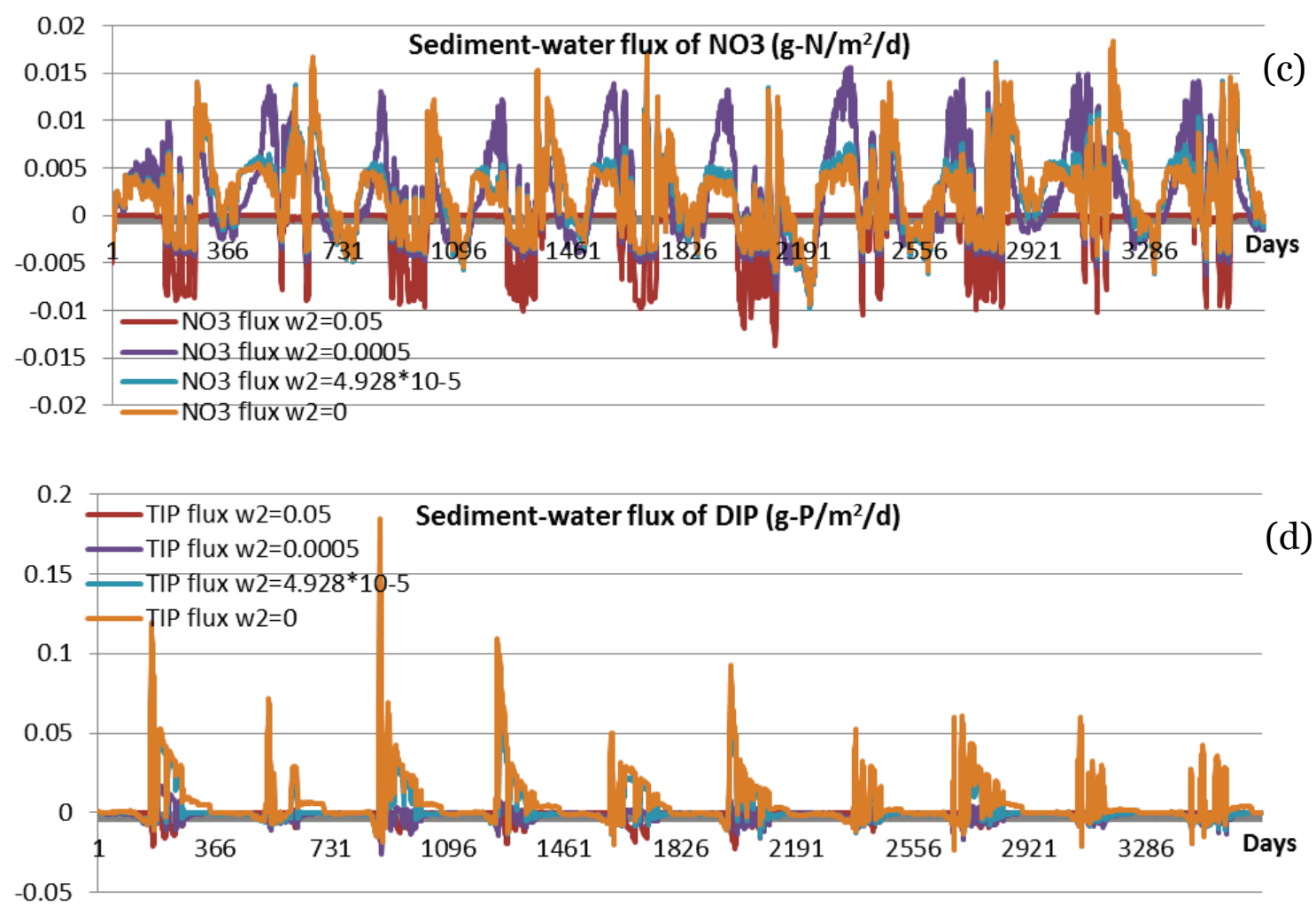


\section{Conclusions}

A benthic sediment diagenesis module has been developed and included in the NSM modules as an option. This new feature required additional model inputs. When this feature is activated, SOD and water-sediment fluxes are internally computed by the sediment diagenesis module for coupling with water column kinetics. Three major processes included in the sediment diagenesis module are: 1) deposition of particulate organic matter from the water column to the sediments, 2) mineralization (or diagenesis) of the particulate organic matter, and 3) reactions and transfers of the reaction products.

Testing and validation studies of the NSMII-benthic sediment diagenesis module were performed by running the same site conditions with the SedFlux and ICM for the Chesapeake Bay dataset. In general, the model verifications with respect to temporal variations of sediment organic and inorganic carbon, nitrogen, and phosphorus concentrations are quite satisfactory compared with results produced from the SedFlux and ICM. The NSMII was able to reproduce SOD and sediment-water nutrient fluxes. Moreover, the sediment diagenesis module was applicable to a wide range of sedimentation conditions and sediment organic contents. There was good agreement between the NSMII predictions and results produced from the SedFlux and ICM for SOD, sediment-water fluxes of $\mathrm{NH}_{4}, \mathrm{NO}_{3}$, DIP, $\mathrm{H}_{2} \mathrm{~S}$ and $\mathrm{CH}_{4}$. Special test cases and sensitivity analysis of the NSMII to the sediment initial conditions, organic matter depositional rates, deep burial velocities, and particle mixing coefficient highlighted process interactions and synergistic effects. It is concluded that the NSMII-benthic sediment diagenesis module will be most useful for applications involving sediment-water interactions to evaluate the effects of benthic sediments on water quality concentrations in aquatic environments.

There are some limitations of the NSMII-benthic sediment diagenesis module that could be improved in the future. The benthic sediment layer is assumed to have constant properties, including the thickness, volume, porosity, bulk density, and solids mass. The NSMII does not simulate or couple with sediment erosion and resuspension processes. Particle deposition and erosion and the resulting effects on bed thickness are not taken into account. Coupling the NSM module with a dynamic benthic sediment 
model within the hydrologic and hydraulic models could overcome some of the weaknesses. 


\section{References}

Berner, R. 1980. Early diagenesis: A theoretical approach. Princeton University Press.

Cerco, C., and T. Cole. 1993. Three-dimensional eutrophication model of Chesapeake Bay. J. Environ. Eng. ASCE 119 (6): 1006-1025.

Cerco, C. F., M. R. Noel, and S. C. Kim. 2004. Three-dimensional eutrophication model of Lake Washington, Washington State. ERDC/EL TR-04-12. Vicksburg, MS: U.S. Army Engineer Research and Development Center.

Chapra, S. C. 1997. Surface Water Quality Modeling. NY, McGraw-Hill.

Chapra, S. C. 1999. Organic carbon and surface water quality modeling. Progress in Environmental Science 1 (1):49-70.

Chapra, S. C., G. J. Pelletier, and H. Tao. 2008. QUAL2K: A Modeling Framework for Simulating River and Stream Water Quality, Version 2.11: Documentation and User's Manual. Medford, MA: Tufts University.

Chapra, S. C., R. K. Gawde, M. T. Auer, R. K. Gelda, and N. R. Urban. 2015. Sed2K: Modeling Lake Sediment Diagenesis in a Management Context. J. Environ. Eng. ASCE 141: 1-13.

Connolly, J. P., and R. B. Coffin. 1995. Model of carbon cycling in planktonic food webs. Journal of Environmental Engineering 121 (10):682-690.

Di Toro, D. M., Paquin, P. R., Subburamu, K., Gruber, D. A., 1990. Sediment oxygen demand model: methane and ammonia oxidation. J. Environ. Eng. ASCE 116: 945-986.

Di Toro, D. M. 2001. Sediment flux modeling. New York, NY: Wiley-Interscience.

Di Toro, D. M., and J. F. Fitzpatrick. 1993. Chesapeake Bay sediment flux model. Technical Report EL-93-2. Vicksburg, MS: U.S. Army Corps of Engineers, Waterways Experiment Station.

Hydrologic Engineering Center (HEC). 2010. HEC-RAS: River analysis system user's reference manual version 4.1. Hydrologic Engineering Center. Davis, CA: U.S. Army Corps of Engineers.

Martin, J. L., 2002. A Review and Evaluation of Sediment Diagenesis Routines for Potential Incorporation into the Water Analysis Simulation Program (WASP) Draft Final Report. Mississippi State University, MS.

Rudd, J. W. and C. D. Taylor. 1980. Methane cycling in aquatic environments. Advanced Aquatic Microbiology 2:77-150.

Shanahan, P., M. Henze, L. Koncsos, W. Rauch, P. Reichert, L. Somlyódy, and P. Vanrolleghem. 1998. River water quality modeling: II. Problems of the art. Water Science \& Technology 38 (11):245-252. 
Zhang, Z., and B. E. Johnson. 2016. Aquatic nutrient simulation modules (NSMs) developed for hydrologic and hydraulic models. ERDC/EL TR-16-1. Vicksburg, MS: U.S. Army Engineer Research and Development Center. 


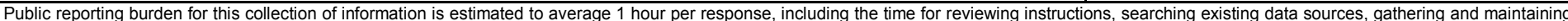

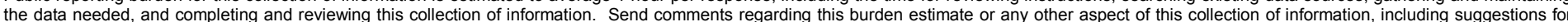

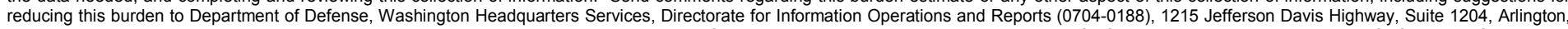

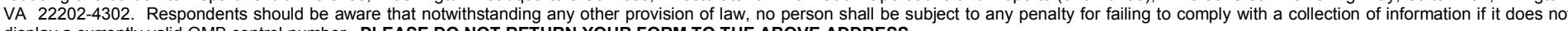
display a currently valid OMB control number. PLEASE DO NOT RETURN YOUR FORM TO THE ABOVE ADDRESS.
1. REPORT DATE (DD-MM-YYYY) 2. REPORT TYPE
July 2016 Final report

3. DATES COVERED (From - To)

\title{
4. TITLE AND SUBTITLE
}

Testing and Validation Studies of the NSMII-Benthic Sediment Diagenesis Module

5a. CONTRACT NUMBER

\begin{abstract}
Testing and Validation Studies of the NSMII-Benthic Sediment Diagenesis Module
\end{abstract}

\begin{tabular}{|l|l|} 
& \\
\hline 6. AUTHOR(S) & 50 \\
Zhonglong Zhang and Billy E. Johnson & \\
\cline { 2 - 2 } & \\
\hline
\end{tabular}

\section{PERFORMING ORGANIZATION NAME(S) AND ADDRESS(ES)}

U.S. Army Engineer Research and Development Center, Environmental Laboratory

3909 Halls Ferry Road

Vicksburg, MS 39180-6199

\section{SPONSORING / MONITORING AGENCY NAME(S) AND ADDRESS(ES)}

Headquarters, U.S. Army Corps of Engineers

Washington, DC 20314-1000

5a. CONTRACT NUMBER

\section{5b. GRANT NUMBER}

5c. PROGRAM ELEMENT NUMBER

5d. PROJECT NUMBER

45745

5e. TASK NUMBER

5f. WORK UNIT NUMBER

8. PERFORMING ORGANIZATION REPORT NUMBER

ERDC/EL TR-16-11

10. SPONSOR/MONITOR'S ACRONYM(S)

HQUSACE

11. SPONSOR/MONITOR'S REPORT NUMBER(S)

\section{DISTRIBUTION / AVAILABILITY STATEMENT}

Approved for public release; distribution unlimited.

\section{SUPPLEMENTARY NOTES}

\section{ABSTRACT}

Nutrient simulation modules (NSMs) have been developed as "plug in" water quality modules for HEC-RAS (Hydrologic Engineering Center-River Analysis System) and other hydrologic and hydraulic models. The NSMs model multiple water quality constituents and biogeochemical processes in the water column. The NSMs consist of two modules: NSMI and NSMII, differing mainly in the number of water quality constituents (state variables) and kinetic processes (transformations) included. The benthic sediment diagenesis module was developed as an option module for coupling with the NSM I and NSMII's water column kinetics. Sediment-water fluxes of dissolved oxygen and nutrients are computed internally rather than prescribed if the benthic sediment diagenesis module is activated. The ability of the NSMII-benthic sediment diagenesis module to correctly predict sediment-water nutrient fluxes and sediment oxygen demand was validated and evaluated against observed data and existing benthic sediment diagenesis models through a series of case studies. These case studies were chosen for representing various sedimentation and environmental conditions in aquatic systems. The simulated sediment-water nutrient fluxes and sediment oxygen demand over time were generally in good agreement with observed data and two model results for all test cases. This report documents testing and evaluation of the NSMII-benthic sediment diagenesis module. The report describes the testing conditions, model inputs, and model results.

\begin{tabular}{|c|c|c|c|c|c|}
\hline \multicolumn{2}{|c|}{$\begin{array}{l}\text { 15. SUBJECT TERMS } \\
\text { Benthic sediment diagenesis module } \\
\text { Biogeochemical processes } \\
\text { HEC_RAS }\end{array}$} & $\begin{array}{l}\text { NSM } \\
\text { Water quality } \\
\text { Hydrology }\end{array}$ & & $\begin{array}{l}\mathrm{Hy} \\
\mathrm{Ch} \\
\mathrm{Sec} \\
\mathrm{Wa}\end{array}$ & $\begin{array}{l}\text { ogic models } \\
\text { cal kinetics } \\
\text { ent transport } \\
\text {-Dissolved oxygen }\end{array}$ \\
\hline \multicolumn{3}{|c|}{ 16. SECURITY CLASSIFICATION OF: } & $\begin{array}{l}\text { 17. LIMITATION } \\
\text { OF ABSTRACT }\end{array}$ & $\begin{array}{l}\text { 18. NUMBER } \\
\text { OF PAGES }\end{array}$ & $\begin{array}{l}\text { 19a. NAME OF RESPONSIBLE } \\
\text { PERSON }\end{array}$ \\
\hline $\begin{array}{l}\text { a. REPORT } \\
\text { UNCLASSIFIED }\end{array}$ & $\begin{array}{c}\text { b. ABSTRACT } \\
\text { UNCLASSIFIED }\end{array}$ & $\begin{array}{l}\text { c. THIS PAGE } \\
\text { UNCLASSIFIED }\end{array}$ & UU & 45 & $\begin{array}{l}\text { 19b. TELEPHONE NUMBER } \\
\text { (include area code) }\end{array}$ \\
\hline
\end{tabular}

